\title{
INFILTRATION AND UNSATURATED FLOW UNDER THE INFLUENCE OF SURFACE MICROTOPOGRAPHY - MODEL SIMULATIONS AND EXPERIMENTAL OBSERVATIONS
}

\author{
A Thesis \\ Submitted to the Graduate Faculty \\ of the \\ North Dakota State University \\ of Agriculture and Applied Science
}

By

Yang Liu

In Partial Fulfillment

for the Degree of

MASTER OF SCIENCE

Major Department:

Civil and Environmental Engineering

June 2013

Fargo, North Dakota 


\section{North Dakota State University Graduate School}

INFILTRATION AND UNSATURATED FLOW UNDER THE INFLUENCE OF SURFACE MICROTOPOGRAPHY - MODEL SIMULATIONS AND

EXPERIMENTAL OBSERVATIONS

By

Yang Liu

The Supervisory Committee certifies that this disquisition complies with North

Dakota State University's regulations and meets the accepted standards for the degree of

\section{MASTER OF SCIENCE}

SUPERVISORY COMMITTEE:

\begin{tabular}{ll} 
& Xuefeng Chu \\
\hline Chair & \\
& Xinhua Jia \\
\hline Zhulu Lin \\
\hline
\end{tabular}

Approved:

March 26, 2014 Date
Dinesh Katti

Department Chair 


\begin{abstract}
Surface microtopography affects fundamental hydrologic processes including infiltration and soil-water percolation at different scales. By means of studying the unsaturated flow, this thesis research is aimed to evaluate the effects of surface microtopography on wetting front moving patterns for rough soil surfaces through both experimental study and HYDRUS modeling. Additional influential factors such as rainfall intensity and soil type are also considered. Laboratory-scale infiltration and unsaturated flow experiments were conducted for different microtopographic surfaces, rainfall intensities, and types of soil; and two- and threedimensional numerical modeling was conducted under the same conditions. The simulated and observed wetting front distributions were compared in this combined experimental and modeling study. It was found that a uniformly distributed wetting front was eventually achieved although soil surfaces had dissimilar topographic characteristics. However, the timing to reach the uniform flat wetting front varied, depending on surface microtopography, soil hydraulic properties, and boundary conditions.
\end{abstract}




\section{ACKNOWLEDGEMENTS}

I would like to first acknowledge my major adviser - Dr. Xuefeng Chu for giving me this opportunity to study at North Dakota State University (NDSU). I am very grateful for his knowledge, wisdoms and encouragement to inspire and lead me through all the steps to complete this thesis.

I am very appreciative of Dr. Xinhua Jia’s kindness and generosity for providing the software packages for my research. Her passion and diligent work have set a good example for

me not only at work but also in life. My gratitude is also for my other committee members: Drs. Zhulu Lin and Yechun Wang. I would like to acknowledge them for their time and efforts on serving as my committee members.

I would like to acknowledge all my colleagues and friends, Yaping Chi, Jun Yang, Daniel Bogart, Leif Sande, and Noah Habtezion, for being galvanizers and helping me during my study. Thanks to Yaping and Jun for their attention starting from the first moment I arrived at NDSU. I feel honored and lucky to have them around me, guiding and helping me through all the difficulties. I also appreciate Daniel Bogart for assisting me in my experiments.

I would like to acknowledge my financial support contributors: the Department of Civil and Environmental Engineering at NDSU for giving me the opportunities serving as a Teaching Assistant, and the National Science Foundation grant No.EAR-0907588 for supporting me with the experimental materials and equipment.

Last but not least, I want to extent my most genuine gratitude to my parents, Yihai and Pengna, and my boyfriend Zhengping for always being there and having faith in me. I could not accomplish my research work without their companies, support, dedication, and love. 


\section{TABLE OF CONTENTS}

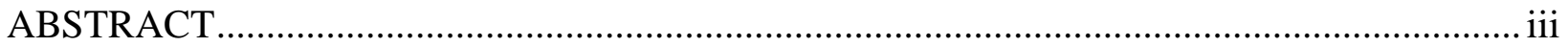

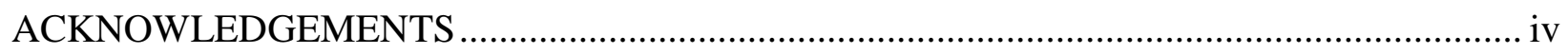

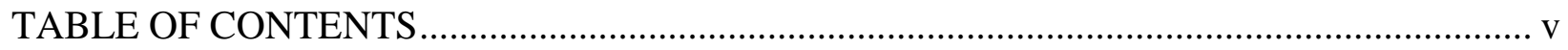

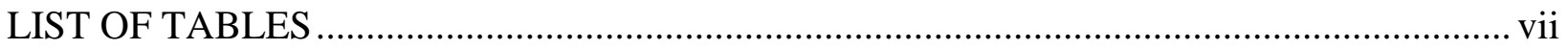

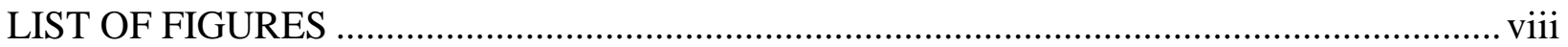

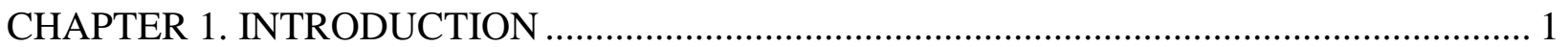

1.1. Overview of Infiltration and Unsaturated Flow under the Influence of Surface

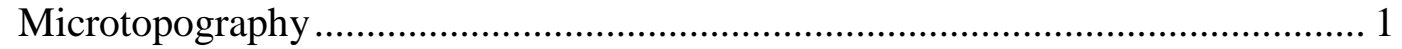

1.1.1. Infiltration affected by surface microtopography ................................. 1

1.1.2. Impacts of microtopography on the interaction between infiltration

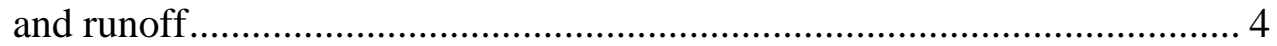

1.1.3. Microtopographic impact on unsaturated flow .................................... 5

1.1.4. Some challenges on studying microtopographic effects in hydrologic

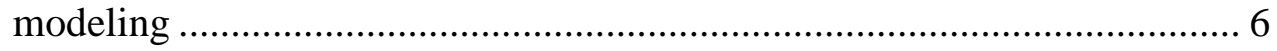

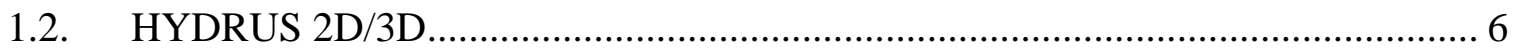

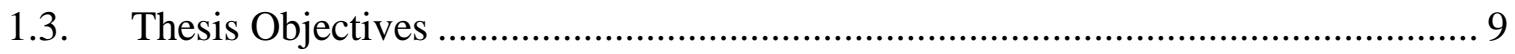

CHAPTER 2. MATERIALS AND METHODS ................................................................ 10

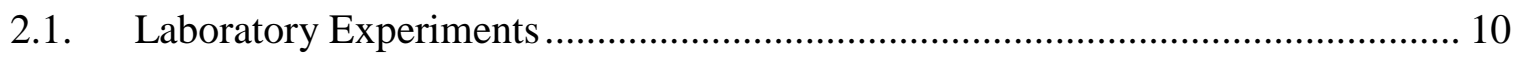

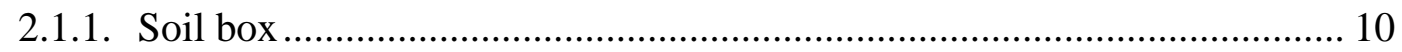

2.1.2. Creation of soil surface topography................................................. 11

2.1.3. Calculations for laboratory experiments ........................................... 13

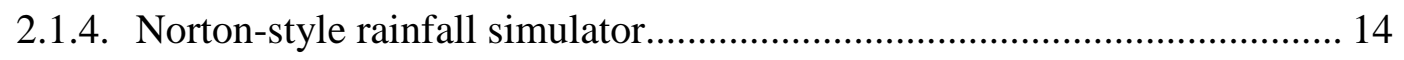

2.1.5. General experimental procedures ....................................................... 14

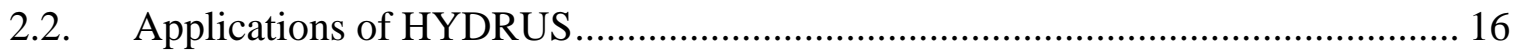


2.3. HYDRUS Modeling Scenarios .................................................................. 19

2.4. Evaluation of Model Performance ………………........................................ 22

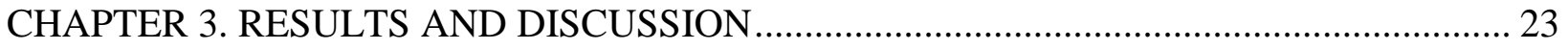

3.1. Scenario One: Soil Water Movement under Three Different Surfaces (Convex, Concave, and Flat)................................................................................................ 23

3.1.1. Distribution of experimental wetting fronts............................................... 23

3.1.2. 2D HYDRUS modeling .......................................................................... 26

3.1.3. Comparison between the observed and simulated wetting front data ........ 30

3.1.4. Microtopographic effects on soil-water movement ..................................... 31

3.1.5. Discussion on the changing pattern of wetting front movement ................ 34

3.2. Scenario Two: Soil Water Movement under Three Different Rainfall Intensities 36

3.2.1. Experimental wetting front movement under three different steady rainfall intensities................................................................................... 36

3.2.2. Comparison between the observed and simulated wetting fronts............... 38

3.2.3. Effects of rainfall intensity on topography-influenced wetting front

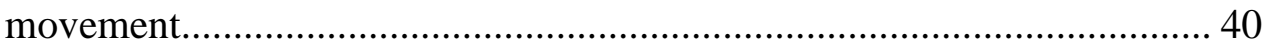

3.3. Scenario Three: Water Movement in Three Different Types of Soil.................... 42

3.3.1. Distribution of experimental wetting front movement within three types of soil......................................................................................... 43

3.3.2. Comparison of the experimental and modeling data .................................. 45

3.3.3. Discussion on the effects of soil type on wetting front movement............. 46

3.4. Modeling of Unsaturated Flow for Complex Topographic Surfaces ..................... 48

CHAPTER 4. SUMMARY AND OVERALL CONCLUSIONS ……………………................ 52

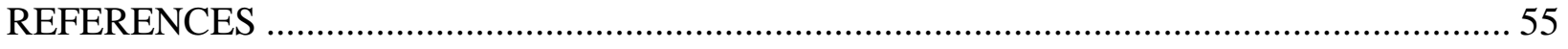




\section{LIST OF TABLES}

$\underline{\text { Table }}$

$\underline{\text { Page }}$

2.1. Soil volumes for the convex, concave, and flat soil surfaces .................................... 14

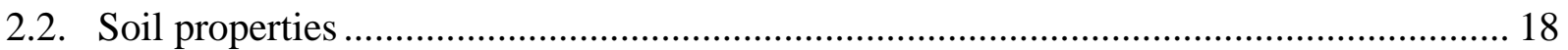

2.3. Soil hydraulic parameters estimated by using Rosetta* ......................................... 18

2.4. Summary of the HYDRUS 2D modeling scenarios ................................................. 19

3.1. Quantitative evaluation of the model performance for the three surfaces ..................... 31

3.2. Comparison of wetting front depths for the three microtopographic surfaces at three

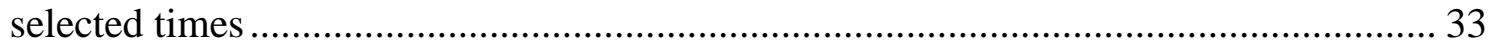

3.3. Quantitative evaluation of the model performance for the three rainfall events ............ 40

3.4. Regression equations of standard deviations of wetting front depths (SD) vs. time (t) for light, moderate, and heavy rainfall events.......................................................... 42

3.5. Selected wetting front depths for the three rainfall events at $t=20 \mathrm{~min} \ldots \ldots \ldots \ldots \ldots \ldots \ldots . . . . . . . .42$

3.6. Quantitative evaluation of the model performance for the three soil types ................... 46

3.7. Regression equations of standard deviations of wetting front depths (SD) vs. time (t) for silty clay loam, silty clay, and loamy sand soils ............................................ 47 


\section{LIST OF FIGURES}

Figure

$\underline{\text { Page }}$

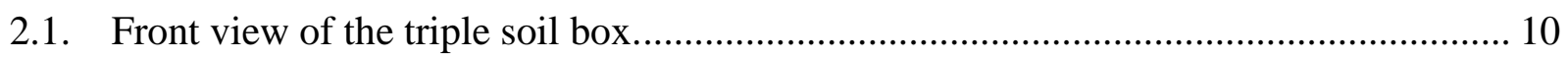

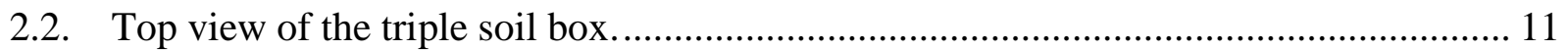

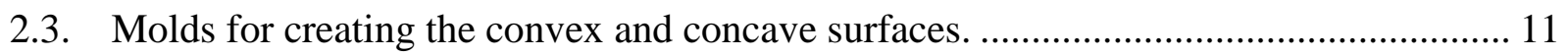

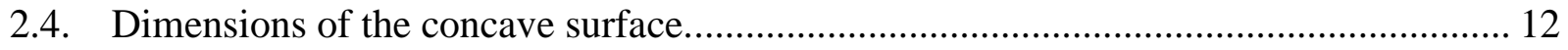

2.5. Design details for experiments and simulations. .............................................. 20

3.1. Distribution of the experimental wetting fronts under the convex soil surface (rainfall $=0.040 \mathrm{~cm} / \mathrm{min}$; duration $=56 \mathrm{~min}$; time interval $=4 \mathrm{~min})$.

3.2. Distribution of the experimental wetting fronts under the concave surface

(rainfall intensity $=0.044 \mathrm{~cm} / \mathrm{min}$; duration $=56 \mathrm{~min}$; time interval $=4 \mathrm{~min}$ )

3.3. Distribution of the experimental wetting fronts under the flat surface (rainfall intensity $=0.044 \mathrm{~cm} / \mathrm{min}$; duration $=56 \mathrm{~min}$; time interval $=4 \mathrm{~min}) . \cdots \cdots \cdots \cdots \cdots \cdots \cdots \cdots \cdots \cdots \cdots$

3.4. Simulated wetting front movement and the distributions of soil water content for convex, concave, and flat surfaces at $\mathrm{t}=10,20,30,40,50$, and $56 \mathrm{~min}$.

3.5. Simulated water content distributions along soil depth at $X=5$ and $10 \mathrm{~cm}$ for the convex, concave, and flat surfaces.

3.6. Comparisons of the observed and simulated wetting front depths for the convex,

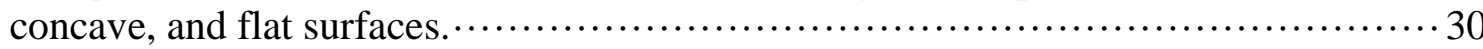

3.7. Temporal distributions of standard deviations of the observed wetting front depths

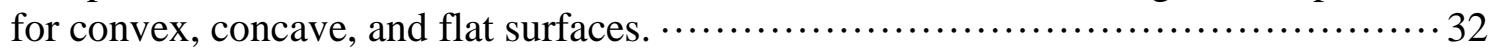

3.8. Soil-water flow directions for the concave and convex surfaces. $\cdots \cdots \cdots \cdots \cdots \cdots \cdots \cdots \cdots \cdots \cdots \cdots$

3.9. Distribution of the experimental wetting fronts for light rainfall (intensity = $0.023 \mathrm{~cm} / \mathrm{min}$; time interval $=12 \mathrm{~min}$; duration $=120 \mathrm{~min}$.

3.10. Distribution of the experimental wetting fronts for moderate rainfall (intensity = $0.043 \mathrm{~cm} / \mathrm{min}$; time interval $=4 \mathrm{~min}$; duration $=56 \mathrm{~min})$.

3.11. Distribution of the experimental wetting fronts for heavy rainfall (intensity $=$ $0.086 \mathrm{~cm} / \mathrm{min}$; time interval $=2 \mathrm{~min}$; duration $=21 \mathrm{~min}$ ). 
3.12. Comparison of observed and simulated wetting fronts for light rainfall (intensity $=$ $0.023 \mathrm{~cm} / \mathrm{min}$ ), moderate rainfall (intensity $=0.043 \mathrm{~cm} / \mathrm{min}$ ), and heavy rainfall

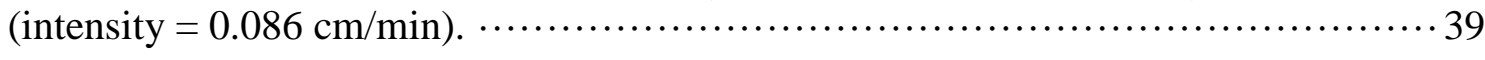

3.13. Temporal distributions of the standard deviation of the observed wetting front for light, moderate, and heavy rainfall events.

3.14. Distribution of the experimental wetting fronts for silty clay loam soil (rainfall intensity $=0.044 \mathrm{~cm} / \mathrm{min}$; time interval $=4 \mathrm{~min}$; duration $=20 \mathrm{~min}$ ).

3.15. Distribution of the experimental wetting fronts for silty clay soil (rainfall intensity $=0.040 \mathrm{~cm} / \mathrm{min}$; time interval $=4 \mathrm{~min}$; duration $=30 \mathrm{~min}$ ).

3.16. Distribution of the experimental wetting fronts for loamy sand (rainfall intensity $=0.044 \mathrm{~cm} / \mathrm{min}$; time interval $=4 \mathrm{~min}$; duration $=56 \mathrm{~min})$.

3.17. Comparison between the observed and simulated wetting fronts for silty clay loam, silty clay, and loamy sand.

3.18. Standard deviation of the observed wetting front depths for silty clay loam with an initial soil moisture content (IC) $=0.15 \mathrm{~cm}^{3} / \mathrm{cm}^{3}$, silty clay with IC $=0.15 \mathrm{~cm}^{3} / \mathrm{cm}^{3}$, and loamy sand with IC $=0.15 \mathrm{~cm}^{3} / \mathrm{cm}^{3}$ for simulation and IC $=0.07 \mathrm{~cm}^{3} / \mathrm{cm}^{3}$ for experiment.

3.19. Three random roughness soil surfaces used for the 3D simulations: (a) surface RR1,

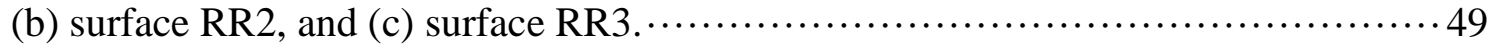

3.20. Wetting front curves for surfaces RR1, RR2, and RR3 at $t=15,30$, and 45 min $(\mathrm{y}=50.0 \mathrm{~cm})$.

3.21. Standard deviation of wetting front depths for surfaces RR1, RR2, and RR3 at $\mathrm{t}=15,30$, and $50 \min (\mathrm{y}=50.0 \mathrm{~cm})$. 


\section{CHAPTER 1. INTRODUCTION}

1.1. Overview of Infiltration and Unsaturated Flow under the Influence of Surface Microtopography

Microtopography refers to small-scale spatial patterns of surface roughness, normally formed by irregular or rough topographic features, such as ridges, channels, shallow depressions, and small mounds. These intrinsic features of soil surface topography have a considerable influence on the behavior of the hydrologic system (Western et al. 2001) and the related hydrologic processes, such as surface depression storage, surface ponding, overland flow generation, infiltration, and soil-water percolation. Infiltration describes the entry of water into a soil matrix from rainfall, irrigation, and snowmelt. Infiltration is one of the major processes in the hydrologic cycle because it plays an important role to determine not only how much water enters into the soil but also the magnitude of water that becomes surface runoff or overland flow (Radcliffe and Šimůnek 2010). After infiltrating into soil, water subsequently moves downward in the form of unsaturated flow driven by gravitational force and soil matric potential. Soil water infiltration and unsaturated flow are affected by numerous factors, such as rainfall intensity, soil type, and topographic conditions. Studies (e.g., Dixon and Earls 2009; Lee et al. 2009; Price 2011) have highlighted the importance and research needs to evaluate the influence of surface microtopography on infiltration and unsaturated flow.

\subsubsection{Infiltration affected by surface microtopography}

As one of the important hydrologic processes, infiltration has been extensively studied theoretically and practically (Musgrave 1955; Philip 1969). This complex hydrologic process is influenced by a number of factors in reality including water supply rate, pore structures of soil particles, spatial variability and distribution of the soil hydraulic properties, initial and boundary 
conditions, temperature, and topography (Musgrave 1955; Western et al. 2001; Shmuel 2013). These factors have been divided into three categories based on their spatial and temporal impacts on infiltration: site, soil, and meteorological characteristics (Haggard et al. 2005). As one of the site characteristics, microtopography refers to small-scale topography or soil roughness and describes the spatial variation of elevation (Römkens and Wang 1986; Aguilar et al. 2009). Ignoring microtopographic variations may lead to significant biases in predicting hydrologic partitioning of rainfall into surface runoff and infiltration (Thompson et al. 2010).

Surface microtopographic variation has been identified as one of the determinants for infiltration rates (Köhne et al. 2011; Darboux et al. 2002). Allmaras et al. (1972) observed increased infiltration from rough surfaces, as well as higher evaporation rates. Moore and Singer (1990) concluded that a greater infiltration rate of the soil was associated with rougher surfaces, even though this relation tended to disappear due to surface sealing when rainfall progressed (Gómez and Nearing 2005).

Huang and Bradford (1990) concluded that better understanding of the relationship between surface roughness and topography-influenced depression storage could effectively help model infiltration and subsequent soil-water percolation in the vadose zone. Many researchers have verified that soil surface roughness enhances the water storage in depressions over the surface (Hansen et al. 1999; Kamphorst et al. 2000; Planchon et al. 2001), which indirectly enhances the infiltration rate (Hairsine et al. 1992). Soil surfaces with rougher topographic conditions have larger surface depression storage and greater ponded water depth (Mitchell and Jones 1978; Onstad 1984). Higher pressure head and larger water-covered area on a rough soil surface may further induce greater infiltration (Dunne et al. 1991; Fox et al. 1997; Fox et al. 1998). 
Microtopography has different scales, which leads to various influences on infiltration (Dunne et al. 1991). Römkens and Wang (1986) categorized surface roughness by soil particle sizes and land surface features as follows: microrelief (particle size $<2 \mathrm{~mm}$ ), random roughness related to cloddiness (100 mm-200 mm), oriented roughness caused by human activities such as tillage (100 mm-200 mm), and high order roughness (slopes of hills). Both random roughness and oriented roughness are usually produced by tillage implements (Allmaras et al. 1966; Guzha 2003). Vázquez Vidal et al. (2005) summarized that soil roughness is often quantified by using roughness indices, such as random roughness (RR) index which is one of the predominant methods used for describing surface microtopography. Since RR only quantifies the vertical irregularities for topography, using this statistical index is insufficient (Vázquez Vidal et al. 2005). Huang and Bradford (1992) combined fractal Brownian motion and Markov-Gaussian process to quantify microtopography in both horizontal and vertical directions. This fractal analysis approach was considered to become a useful tool for analyzing soil surface microtopography (Vázquez Vidal et al. 2005; Chi et al. 2012). In addition, it is deficient to quantify and characterize microtopography without considering scales (Huang and Bradford 1990).

At the scale of microrelief (particle size $<2 \mathrm{~mm}$ ), great densities of macropores exist on higher parts of the surfaces, resulting in greater hydraulic conductivities than the adjacent depressions (Dunne et al. 1991). Soil entities under rough surfaces usually have larger porosity and higher hydraulic conductivity than those under smooth surfaces, which is vital to increase infiltration (Zobeck and Onstad 1987). Besides, microtopographic changes from tillage also influence infiltration. Tillage-induced soil roughness with increased soil porosity enhances infiltration into soils (Guzha 2003). It was observed by Guzha (2003) that the infiltration rates of 
the tilled areas were initially very high but decreased over time because of the soil structural deterioration. In addition, the initial infiltration rate was $12.4 \%$ to $140 \%$ higher than that in the later stage depending on the tillage methods (Guzha 2003).

\subsubsection{Impacts of microtopography on the interaction between infiltration and runoff}

Rossi and Ares (2012) modeled infiltration and overland flow processes by considering depression storage which was determined by surface microtopography. They stated that horizontal spatial variability of soil properties, including surface topography, significantly influenced the field-scale infiltration. The importance of surface microtopography and its influences on runoff generation, overland flow, and baseflow have also been discussed and emphasized by many researchers (e.g., Darboux et al. 2002; Lei et al. 2006; Chu et al. 2010; Smith et al. 2011; Price 2011). Fiedler and Ramirez (2000) developed a numerical method to simulate two-dimensional overland flow and infiltration processes on designated topographic surfaces. They verified that the dynamic interaction between surface runoff and infiltration was caused by surface topography and other factors such as soil properties and rainfall. In arid and semi-arid regions, infiltration can also be affected by the development of water-repellent areas (Lipsius and Mooney 2006), which is relevant to soil surface topographic variations (Biemelt et al. 2005).

General agreement is that microtopography has important effects on runoff at fine spatial scales and increases infiltration, which reduces overland flow (Bergkamp 1998). Variably unsaturated flow in the vadose zone catalyzes the partitioning of infiltration and runoff from rainfall (Zhu and Mohanty 2006), which is also affected by surface microtopographic variations. Ignorance of this effect may lead to bias of prediction for runoff generation (Thompson et al. 2010). 


\subsubsection{Microtopographic impact on unsaturated flow}

The soil-water movement under the rough surface topography initially attributes to strong soil matric potential (Hillel 1998; Sande and Chu 2012). Surface microtopography induces lateral flow movement near the soil surface, and this movement degenerates along soil depth (Sinai and Dirksen 2006). However, gravity force gradually becomes the governing force over time (Hillel 1998; Sande and Chu 2012). In dry soils, the water potential gradient dominates infiltration at the beginning and the effect of gravitational force can be negligible. When soils are close to saturation, the effects of matric potential decrease and infiltration is primarily driven by the gravitational force (Philip 1957). It is of importance to investigate the horizontal flow moving tendency by 2D/3D modeling underneath surface microtopography including peaks and depressions (Hillel 1998). Lipsius and Mooney (2006) found that lateral movement of unsaturated flow "spreads” the wetting front of soil water. Similarly, spatial variability of soil-water moving patterns can be dominated by the selected site characteristics (van Schaik 2009). Therefore, infiltration was not homogeneous underneath uneven surfaces (Esteves et al. 2000).

Wetting front exhibits a clear boundary between the upper wet part and the lower dry part of soil (Kirkham 2005). Few combined experimental and modeling studies have been carried out to investigate the influence of surface microtopography on wetting front movement. Sande and Chu (2012) observed wetting front movement under smooth and rough surfaces in their experiments and described the distributions of wetting front for the two different microtopographic conditions. They investigated the effects of microtopography on soil-water flow via quantifying the spatial variability in wetting front movement in their small scale laboratory work. Based on their experiments for large and small soil boxes, Sande and Chu 
(2012) concluded that the wetting front movement was "faster" under higher peaks and smooth surfaces compared with the adjacent lower depressions, and that the microtopographic effects on wetting front movement were still strong for deeper soil and longer-duration rainfall. Sinai and Dirksen (2006) observed that during the initial stage of percolation, the wetting front was parallel to the soil surface. As the front moved deeper, the effect of soil surface microtopography became weaker and the wetting front became horizontally homogeneous.

\subsubsection{Some challenges on studying microtopographic effects in hydrologic modeling}

Surface microtopography is essential to determining many major variables in hydrologic analysis and it is critical to better understanding of the physical mechanisms and modeling of hydrologic processes (Chu et al. 2012; Sande and Chu 2012). However, the topographic importance has been underestimated not only in some theoretical assumptions but also in many hydrologic models (Price 2011).

The topographic index (TI) (Beven and Kirkby 1979) was used to describe topographic conditions. This index has been used in some hydrologic models. Unfortunately, highly generalized TI does not alter the mean basin TI greatly in some study areas (McGuire et al 2005; Price et al. 2011). Moreover, those models that used TI could not accurately predict water table (Burt and Butcher 1985; Jordan 1994; Moore and Thompson 1996; Rodhe et al. 1996). The major problem is that this index insufficiently characterizes the topographic characteristics (Price 2011). Low resolution of digital terrain data is the reason why TI brought errors in predictions (Beven and Kirkby 1979).

\subsection{HYDRUS 2D/3D}

HYDRUS is a windows-based software package. It can be efficiently used for simulating variably unsaturated flow and solute transport (Šimůnek et al. 2012). There are three different 
versions of the HYDRUS software: HYDRUS-1D (Šimůnek et al. 2005), HYDRUS-2D (Šimůnek et al. 1998), and HYDRUS (2D/3D) (Šimůnek et al. 2007). The development from HYDRUS-2D to HYDRUS (2D/3D) makes this software more sophisticated and user-oriented, but their fundamental theory and capabilities are similar. The flow region may contain uniform and non-uniform soils.

The HYDRUS modeling system contains several components: GEOMETRY, MESHGEN, FORTRAN, and GRAPHICS (Šimůnek et al. 2007). GEOMETRY is a computeraid-design program that supports both drawing and importing/exporting geometric domains; MESHGEN is capable of designing and discretizing flow domain in a graphical mode generated in GEOMETRY into irregular triangular elements; FORTRAN is capable of solving the Richards' equation to simulate two- and three-dimensional unsaturated water flow through soil profiles; and GRAPHICS can export output data in two forms: graphs and animations (Šimůnek et al. 2007).

Rocha et al. (2006) conducted a sensitivity analysis for a set of soil hydraulic parameters by using HYDRUS, including saturated water content $\left(\theta_{s}\right)$, residual water content $\left(\theta_{r}\right)$, saturated hydraulic conductivity $\left(K_{s}\right)$, hydraulic property shape factor $(n)$, shape factor in the soil water retention curve $(\alpha)$, and pore-connectivity parameter $(l)$. A constant pressure head was specified as the upper boundary condition; free-drainage conditions were prescribed for the bottom; and no flux boundary was assumed for the two sides of the flow domain. The sensitivity analysis results showed that pressure heads in the soil profile were more sensitive than both cumulative outlet fluxes and soil water contents. Based on their HYDRUS modeling, the sensitivity ranking of the soil hydraulic parameters had the following order: $n>\theta_{s}>K_{s}>\theta_{r}>\alpha>l$. 
Applications of HYDRUS relate to modeling of steady or transient water flow, solute transport, and heat transfer, including short-term and one-dimensional laboratory column flow or transport simulations, as well as more complex, long-duration, and multiple dimensional field studies (Šimůnek et al. 2012). HYDRUS can simulate the flow and transport occurring in the vertical plane, in the horizontal plane, or in a three-dimensional region. The water flow model of HYDRUS can deal with prescribed variable and constant pressure or flux boundaries, and specified gradient boundary conditions. The governing equations for flow and transport are solved using the Galerkin finite element schemes (Šimůnek et al. 2007; Zhou et al. 2007; Yu and Zheng, 2010).

Studies (Köhne et al. 2011; Rocha et al. 2006; Hassan et al. 2005; Schmalz et al. 2003) indicated that HYDRUS shows strong potential and promise to be an effective tool for simulating soil-water flow characteristics and its movement in the unsaturated zone. In addition, HYDRUS also was a pillar for the research on investigating and designing drip irrigation (Skaggs et al. 2004) through analyzing soil water dynamics.

Zhou et al. (2007) compared HYDRUS 2D with their alternate partial root zone drip irrigation model (APRI-model). They compared the observations of soil moisture contents with the simulations by APRI-model and HYDRUS 2D and evaluated the effects of root water uptake on soil water dynamics. The upper boundary in HYDRUS was assumed as prescribed flux, prescribed pressure head, and atmospheric boundary conditions for an irrigation event. The authors concluded that HYDRUS slightly overestimated the soil moisture content in shallow soil due to root distribution and root density. However, HYDRUS predicted the overall soil moisture contents accurately. 


\subsection{Thesis Objectives}

This thesis research involves both laboratory experiments and HYDRUS modeling. It covers the research topics of surface microtopography, unsaturated flow, and HYDRUS modeling. In the study, wetting front movement is observed under three different soil surfaces (concave, convex, and flat surfaces) by maintaining all the other controlled factors such as initial and boundary conditions, as well as soil type and bulk density. In addition, the influences of two other control factors (soil type and rainfall intensity) on soil-water movement are examined for the concave surface. The specific objectives of this study are 1) to evaluate the influence of surface microtopography on wetting front movement with a special focus on the spatial and temporal changing patterns of wetting front; 2) to analyze the moving directions of unsaturated flow influenced by surface microtopography; and 3) to examine the control factors for wetting front movement including surface microtopography, rainfall intensity, and soil type. This research is important for better understanding the characteristics of unsaturated flow under the influence of surface microtopography. 


\section{CHAPTER 2. MATERIALS AND METHODS}

\subsection{Laboratory Experiments}

\subsubsection{Soil box}

A triple soil box was made with plexiglass boards (Fig. 2.1) (Sande 2011). The top of the triple soil box is open to fill soil (Figs. 2.2). The bottom of the box is releasable. Each sub-box is $20 \mathrm{~cm}$ wide, $20 \mathrm{~cm}$ long, and $30 \mathrm{~cm}$ high. To better control the soil bulk density, the box was vertically divided into different layers for soil packing (see the red lines), and each layer is $5 \mathrm{~cm}$ high (Fig. 2.1). The bottom of the triple soil box has several small holes for draining water (Fig. 2.2), and the diameter of each hole is $1 \mathrm{~cm}$. A metallic screen is attached to the bottom to avoid the leakage of soil.

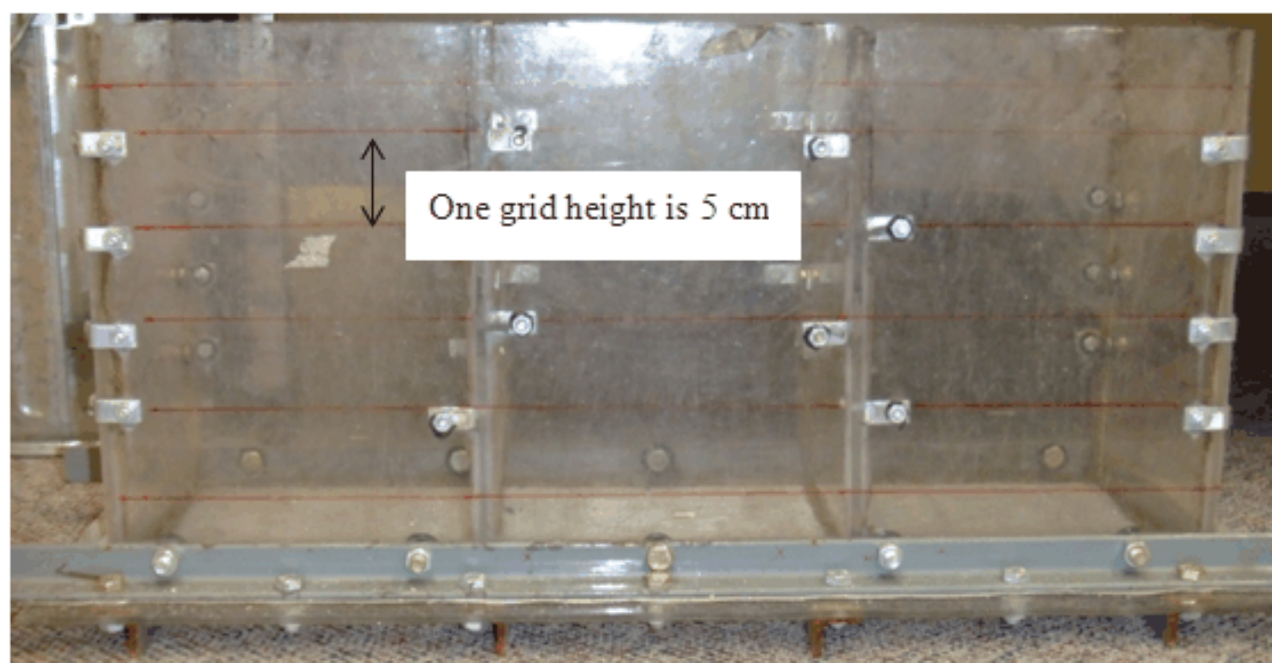

Fig. 2.1. Front view of the triple soil box. 


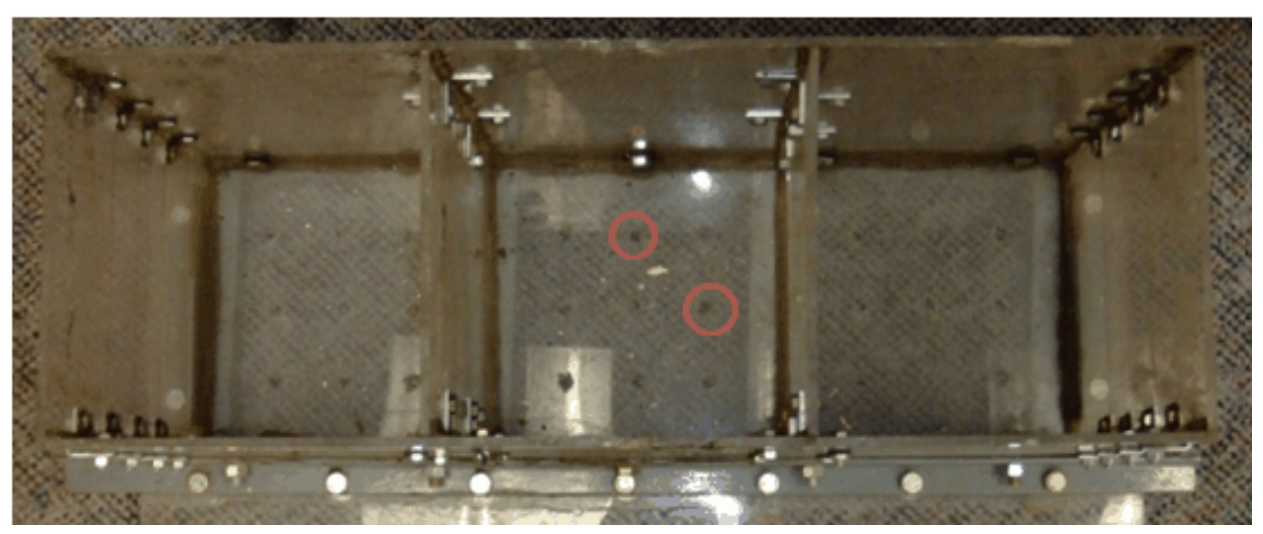

Fig. 2.2. Top view of the triple soil box.

\subsubsection{Creation of soil surface topography}

Since the focus of this study is on the impact of microtopography on infiltration and soilwater movement, different soil surfaces are needed. Therefore, a mold for each sub-box was made in order to form a curved surface. The designed surfaces include convex and concave surfaces (Fig. 2.3), as well as a flat surface.

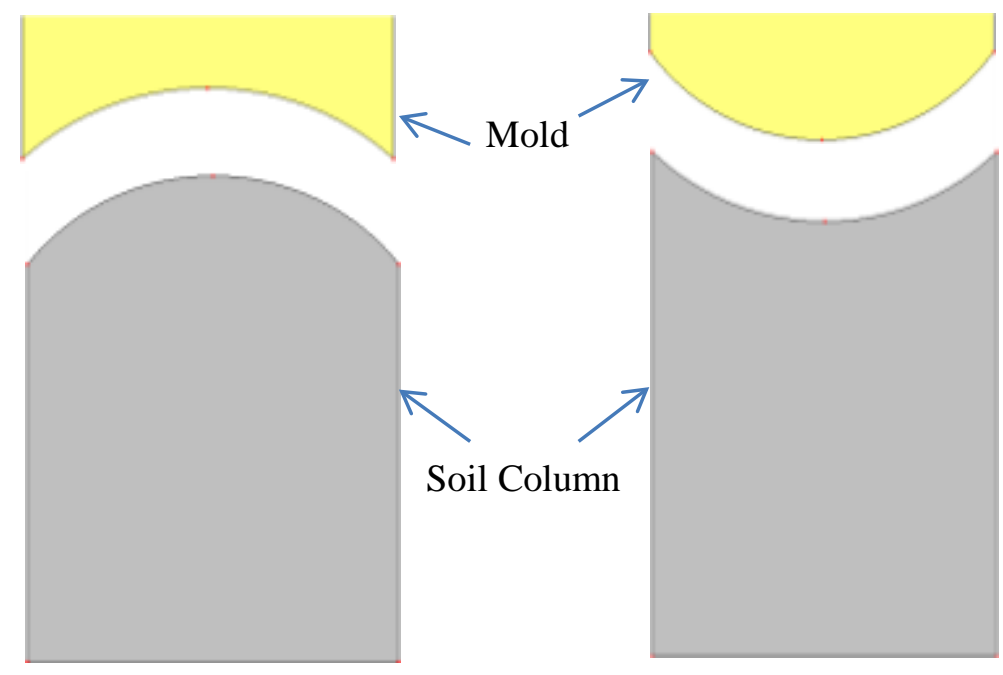

(a) Convex surface

(b) Concave surface

Fig. 2.3. Molds for creating the convex and concave surfaces. 
The two-dimensional geometry of the surface topography mold is an arc of a specified circle. The circle is determined based on three points (A, B and E in Fig. 2.4) which are located on the boundary of a $5 \mathrm{~cm}$ deep soil domain (the rectangle ABDC in Fig. 2.4). The three points (A, B, and E, Fig. 2.4), are on the boundary of the concave soil surface. Points A and B are located at the top of the first soil layer, and $\mathrm{E}$ is at the center of the bottom. Thus, the boundary of the concave surface is an arc of the circle. For the rectangle ABDC in Fig. 2.4, AB $=\mathrm{CD}=20$ $\mathrm{cm} ; \mathrm{AC}=\mathrm{BD}=5 \mathrm{~cm}$; and their corresponding coordinates are A $(0,5), \mathrm{B}(20,5), \mathrm{C}(0,0), \mathrm{D}(20$, 0 ), and $\mathrm{E}(10,0)$. In Fig. 2.4, $\mathrm{AO}=\mathrm{BO}=\mathrm{R}=12.5 \mathrm{~cm}, \mathrm{EF}=5 \mathrm{~cm}, \mathrm{OF}=7.5 \mathrm{~cm}$, and $\theta=53.13^{\circ}$. The area of $\mathrm{OAB}$ is equal to $144.89 \mathrm{~cm}^{2}$ and the area of AEB is $69.89 \mathrm{~cm}^{2}$. The area of AEB forms the concave surface in Fig 2.3b. The area of the colored region in Fig. 2.4 is $30.11 \mathrm{~cm}^{2}$, which is within the first layer of the soil column under the concave surface.

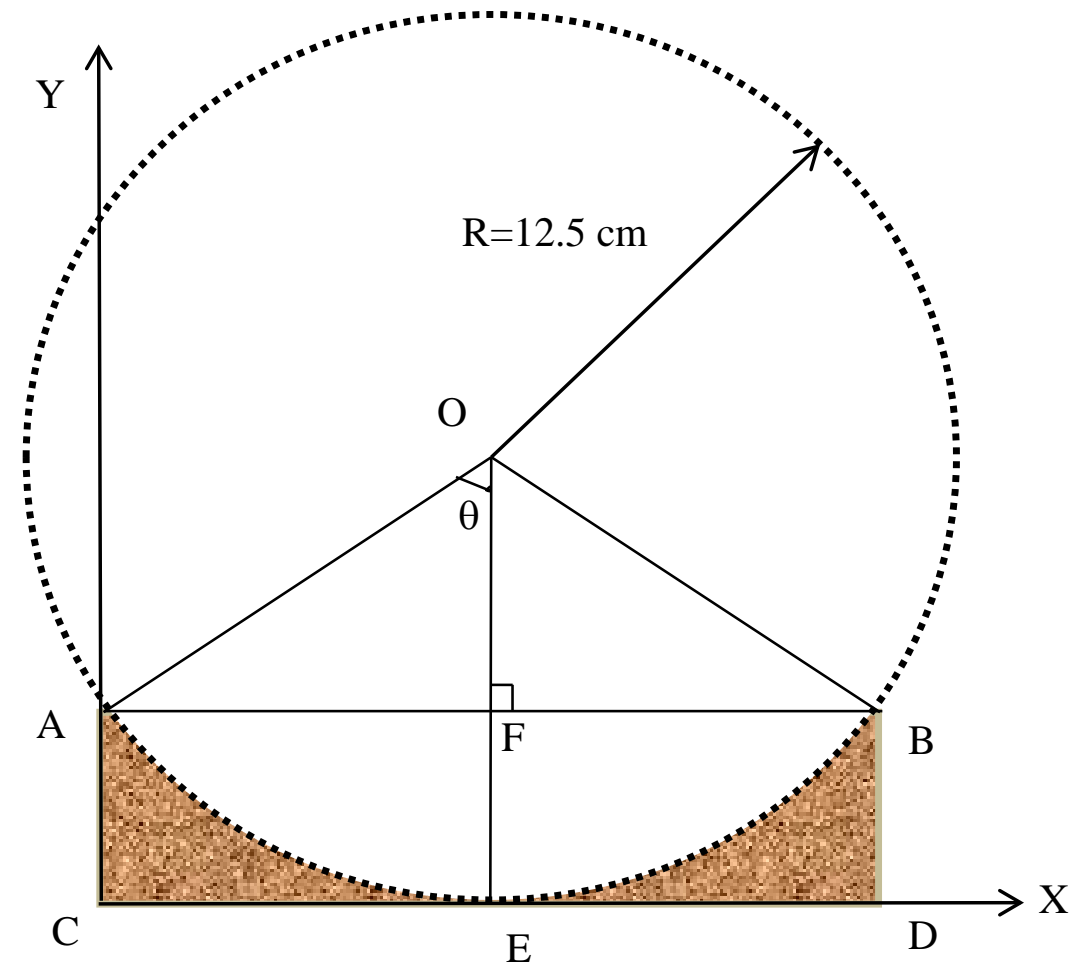

Fig. 2.4. Dimensions of the concave surface. 


\subsubsection{Calculations for laboratory experiments}

The bulk density $\rho_{b}\left(\mathrm{~g} / \mathrm{cm}^{3}\right)$ can be expressed as:

$$
\rho_{b}=\frac{M_{\text {soil }}}{V_{\text {total }}}
$$

where $M_{\text {soil }}$ is the mass of the oven dry soil, and $V_{\text {total }}$ is the total volume including soil, water, and air volumes within the soil column. The total mass $M_{\text {total }}$ is the sum of water mass $M_{\text {water }}$ and soil mass $M_{\text {soil }}$ :

$$
M_{\text {total }}=M_{\text {soil }}+M_{\text {water }}
$$

then gravimetric water content $\omega$ is given by (Hillel 1998):

$$
\omega=\frac{M_{\text {water }}}{M_{\text {soil }}}
$$

Substitute Eq. (3) into Eq. (2):

$$
M_{\text {total }}=M_{\text {soil }}(1+\omega)
$$

In addition, gravimetric water content $\omega$ can be converted to volumetric water content $\theta$ by using soil bulk density $\rho_{b}$ and water density $\rho_{w}$ (Hillel 1998):

$$
\theta=\omega \times \rho_{b} / \rho_{w}
$$

Based on the aforementioned equations and the dimensions of a topographic surface, the mass and volume of the soil column can be determined. The soil columns for both concave and convex surfaces were divided into five layers, while the soil column for the flat surface included four layers (Table 2.1). Each soil layer was $5 \mathrm{~cm}$ deep. The soil volumes of the first layers were 1397.8, 602.2, and $2000.0 \mathrm{~cm}^{3}$ for the convex, concave, and flat surfaces, respectively. The volume of all other soil layers was $2000.0 \mathrm{~cm}^{3}$ for all the three surfaces (Table 2.1). Thus, the 
total volumes of soil packed into the soil boxes were $9397.8,8602.2$, and $8000.0 \mathrm{~cm}^{3}$ for the convex, concave, and flat surfaces, respectively (Table 2.1).

Table 2.1. Soil volumes for the convex, concave, and flat soil surfaces

\begin{tabular}{|c|c|c|c|}
\hline & $\begin{array}{c}\text { Convex surface } \\
\text { (5 layers) }\end{array}$ & $\begin{array}{c}\text { Concave surface } \\
\text { (5 layers })\end{array}$ & $\begin{array}{c}\text { Flat surface } \\
\text { (4 layers })\end{array}$ \\
\hline Volume for $1^{\text {st }}$ layer $\left(\mathrm{cm}^{3}\right)$ & 1397.8 & 602.2 & 2000.0 \\
\hline Volume for $2^{\text {nd }}-5^{\text {th }}\left(4^{\text {th }}\right)$ layer $\left(\mathrm{cm}^{3}\right)$ & 2000.0 & 2000.0 & 2000.0 \\
\hline Total volume $\left(\mathrm{cm}^{3}\right)$ & 9397.8 & 8602.2 & 8000.0 \\
\hline
\end{tabular}

Note: Each soil layer is $5 \mathrm{~cm}$ deep.

\subsubsection{Norton-style rainfall simulator}

To create different intensities of rainfall, the Norton-style rainfall simulator was used for the experiments. This simulator has four oscillating Vee Jet nozzles, and is capable of simulating natural rainfall characteristics such as raindrop size, terminal velocity, energy, and spatial distribution (Meyer and Harmon 1979). Following the experimental studies by Sande (2011), Sande et al. (2011), and Sande and Chu (2012), a rainfall intensity of $2.64 \mathrm{~cm} / \mathrm{hr}$ was chosen for most of the experiments in order to have a longer duration and to clearly observe the patterns of wetting front movement in the silty clay soil from Buxton, ND (to be detailed in Section 2.2). In addition, rainfall intensities of 1.38 and $5.16 \mathrm{~cm} / \mathrm{hr}$ were applied for two other experiments that had different analysis purposes.

\subsubsection{General experimental procedures}

All experiments were conducted by following the procedures detailed by Sande et al. (2011) and Sande and Chu (2012). In soil preparation, air-dry soil was mixed with water to reach the target initial moisture content of $0.15 \mathrm{~cm}^{3} / \mathrm{cm}^{3}$. Since the soil water in the air-dry soil was 
much less than the aimed initial moisture content of $0.15 \mathrm{~cm}^{3} / \mathrm{cm}^{3}$, extra water was sprayed onto the air-dry soil. The soil was stirred with the water until they were uniformly mixed.

The corresponding surface mold for each soil surface (concave, flat, or convex) was attached to the triple soil box. The box was reversed upside down, and then the bottom of the triple soil box was removed for soil packing. The soil box was reversed back and the mold was removed after soil packing.

The amount of soil calculated for each layer (Table 2.1) was weighed. The soil was then packed into each sub-box layer by layer. A brush was used to smooth the soil surface for every layer. A tool with a wide and flat end was used to pack the soil within the specified volume of each layer to achieve the target bulk density. For each experiment, a soil sample from each subbox was taken for the measurement of the actual initial moisture content. The measured actual initial moisture content data were used for the initial condition in the HYDRUS 2D modeling.

After soil packing for all sub-boxes, the bottom of the triple soil box and the metallic screen were installed back. Then, the triple soil box was reversed to the normal position and the mold was removed. At last, the triple soil box was kept in the laboratory for 24 hours at the room temperature to achieve a uniform distribution of soil moisture across the entire soil matrix.

During the 24 hours, the triple soil box was covered to maintain the moisture condition.

In the experiments, the wetting front depths were recorded with a time interval of 1.0 2.0 min, depending on the experimental conditions. The wetting front depths were measured at 5 locations for the convex and concave surfaces, and at 2 locations for the flat surface. The related details will be described in Chapter 3. 


\subsection{Applications of HYDRUS}

HYDRUS was used to model the unsaturated flow along the designed soil columns in this study. The simulated wetting front depths and the distributions of moisture contents under different conditions were compared. The soils were homogeneous with controlled bulk densities and initial moisture contents. Transient unsaturated flow was assumed for the modeling. The governing equation for modeling the 2D unsaturated flow can be expressed as ( ̌̌imůnek et al.1999):

$$
\frac{\partial \theta(x, z, t)}{\partial t}=\frac{\partial}{\partial x}\left[K(h) \frac{\partial h(x, z, t)}{\partial x}\right]+\frac{\partial}{\partial z}\left[K(h) \frac{\partial h(x, z, t)}{\partial z}\right]+\frac{\partial}{\partial z} K(h)-S(h)
$$

where $\theta$ is the volumetric moisture content; $h$ is the soil water pressure head; $x$ is the horizontal coordinate; $z$ is the vertical coordinate; $K$ is the hydraulic conductivity; $t$ is the time; and $S(h)$ is a sink function.

In addition to Eq. 6, the van Genuchten-Mualem model was used to describe the nonlinear relationship between soil water pressure head and unsaturated soil water content (Šimůnek et al. 1999):

$$
\begin{aligned}
& \theta(h)= \begin{cases}\theta_{r}+\frac{\theta_{s}-\theta_{r}}{\left(1+|\alpha h|^{n}\right)^{1-1 / n}} & h \geq 0 \\
\theta_{z} & h \geq 0\end{cases} \\
& K\left(S_{e}\right)=K_{s} S_{e}^{L}\left(1-\left(1-S_{e}^{n L /(n-1)}\right)^{(1-1 / n)}\right)^{2}
\end{aligned}
$$

where,

$$
S_{e}=\frac{\theta-\theta_{r}}{\theta_{s}-\theta_{r}}
$$


where $\theta_{s}$ is the saturated water content; $\theta_{r}$ is the residual water content; $S_{e}$ is the relative saturation; $\alpha$ is a soil water retention parameter relevant to the inverse of the air-entry suction; $L$ is the pore connectivity and tortuosity factor (it is normally 0.5 ); and $n$ is a soil water retention parameter, describing the pore-size distribution. (Jacques et al. 2002, Šimůnek et al. 2002)

The initial condition can be expressed as:

$$
\theta(x, z, 0)=\theta_{0}(x, z)
$$

where $\theta_{0}(x, z)$ is the initial soil moisture content measured in the laboratory.

A constant flux was prescribed as the upper boundary condition for the soil surface in this study (Šimůnek et al. 2007; Radcliffe and Šimůnek 2010):

$$
\sigma(x, z, t)=\left[K(h) \frac{\partial h(x, z, t)}{\partial x}+K(h) \frac{\partial h(x, z, t)}{\partial z}+K(h)\right] n_{i}
$$

where $\sigma(x, z, t)$ is the constant flux at location $(x, z)$ at time $t ; n_{i}$ is the components of the outward unit vector to boundary.

The Galerkin finite element method is used to numerically solve the two-dimensional Richards' equation in HYDRUS. The parameters for the water retention curve and unsaturated hydraulic conductivity were estimated through the van Genuchten (1980) constitutive relationships. Soil hydraulic parameters were predicted by using the Rosetta software package (Schaap et al. 2001) based on the physical properties of the soils. Table 2.2 shows the basic soil property information and Table 2.3 shows the values of the estimated soil hydraulic parameters used in the modeling. 
Table 2.2. Soil properties

\begin{tabular}{|c|c|c|c|c|}
\hline \multirow{2}{*}{ Soil type } & \multicolumn{3}{|c|}{ Soil texture } & \multirow{2}{*}{$\begin{array}{c}\text { Bulk density } \\
\left(\mathrm{g} / \mathrm{cm}^{3}\right)\end{array}$} \\
\cline { 2 - 4 } & Sand (\%) & Silt (\%) & Clay (\%) & 1.40 \\
\hline Loamy sand** & 80.30 & 14.60 & 5.10 & 1.05 \\
\hline Silty clay (Buxton)* & 11.88 & 42.01 & 46.13 & 1.09 \\
\hline Silty clay (Fargo)* $^{*}$ & 4.20 & 46.70 & 49.10 & 1.00 \\
\hline Silty clay loam* & 4.40 & 59.70 & 35.90 & \\
\hline
\end{tabular}

* These unpublished data are provided by the overland flow laboratory in the

Department of Civil Engineering, North Dakota State University.

**Published data (Sande 2011).

Table 2.3. Soil hydraulic parameters estimated by using Rosetta*

\begin{tabular}{|c|c|c|c|c|c|c|}
\hline Soil type & $\begin{array}{c}\theta_{\mathrm{r}}{ }^{\mathrm{a}} \\
\left(\mathrm{cm}^{3} / \mathrm{cm}^{3}\right)\end{array}$ & $\begin{array}{c}\theta_{\mathrm{s}}{ }^{\mathrm{b}} \\
\left(\mathrm{cm}^{3} / \mathrm{cm}^{3}\right)\end{array}$ & $\begin{array}{c}\alpha^{\mathrm{c}} \\
(1 / \mathrm{cm})\end{array}$ & $n^{\mathrm{d}}$ & $\begin{array}{c}K_{s}{ }^{\mathrm{e}} \\
(\mathrm{cm} / \mathrm{min})\end{array}$ & $l^{\mathrm{f}}$ \\
\hline $\begin{array}{c}\text { Loamy } \\
\text { sand }\end{array}$ & 0.041 & 0.407 & 0.058 & 1.870 & 0.197 & 0.500 \\
\hline $\begin{array}{c}\text { Silty clay } \\
\text { (Buxton) }\end{array}$ & 0.045 & 0.580 & 0.013 & 1.304 & 0.025 & 0.500 \\
\hline $\begin{array}{c}\text { Silty clay } \\
\text { (Fargo) }\end{array}$ & 0.060 & 0.579 & 0.052 & 1.161 & 0.029 & 0.500 \\
\hline $\begin{array}{c}\text { Silty clay } \\
\text { loam }\end{array}$ & 0.065 & 0.600 & 0.019 & 1.240 & 0.006 & 0.500 \\
\hline
\end{tabular}

${ }^{\mathrm{a}} \theta_{r}$ is the residual soil moisture content.

${ }^{\mathrm{b}} \theta_{s}$ is the saturated soil moisture content.

${ }^{\mathrm{c}} \alpha$ is relevant to the inverse of the air-entry suction.

${ }^{\mathrm{d}} n$ is water retention curve parameter.

${ }^{\mathrm{e}} K_{s}$ is the saturated hydraulic conductivity.

${ }^{\mathrm{f}} \mathrm{l}$ is the pore connectivity parameter.

*Schaap et al. (2001).

The bulk density of silty clay loam (Table 2.2) is smaller than the normal range for this soil $\left(1.2-1.3 \mathrm{~g} / \mathrm{cm}^{3}\right)$. The low bulk density of silty clay loam is possible because the percentage of sand in the silty clay loam is very low, close to that of the silty clay from Fargo. The 
percentage of silt in the silty clay loam is $13 \%$ and approximately $18 \%$ higher than the silty clay soils from Fargo and Buxton, respectively (Table 2.2).

\subsection{HYDRUS Modeling Scenarios}

In this HYDRUS modeling study, three scenarios related to surface microtopography, rainfall intensity, and soil type were considered based on the corresponding experiments. Each scenario further included three modeling cases for different conditions. Details on the HYDRUS modeling scenarios are shown in Table 2.4 and Fig. 2.5.

Table 2.4. Summary of the HYDRUS 2D modeling scenarios

\begin{tabular}{|c|c|c|c|c|c|}
\hline Models & Experiments & Surface & Rainfall & $\begin{array}{c}\text { Initial moisture } \\
\text { condition } \\
\left(\mathrm{cm}^{3} / \mathrm{cm}^{3}\right)\end{array}$ & Soil type \\
\hline \multicolumn{6}{|c|}{ Scenario of surface microtopography } \\
\hline Model 1 & Experiment 1 & Convex & Moderate & 0.170 & \multirow{3}{*}{$\begin{array}{l}\text { Silty clay } \\
\text { (Buxton) }\end{array}$} \\
\hline Model 2 & Experiment 2 & Concave & Moderate & 0.144 & \\
\hline Model 3 & Experiment 3 & Flat & Moderate & 0.160 & \\
\hline \multicolumn{6}{|c|}{ Scenario of rainfall intensity } \\
\hline Model 4 & Experiment 4 & Concave & Light & 0.130 & \multirow{3}{*}{$\begin{array}{l}\text { Silty clay } \\
\text { (Buxton) }\end{array}$} \\
\hline Model 5 & Experiment 5 & Concave & Moderate & 0.150 & \\
\hline Model 6 & Experiment 6 & Concave & Heavy & 0.130 & \\
\hline \multicolumn{6}{|c|}{ Scenario of soil type } \\
\hline Model 7 & Experiment 7 & Concave & Moderate & 0.146 & Silty clay loam \\
\hline Model 8 & Experiment 8 & Concave & Moderate & 0.136 & $\begin{array}{c}\text { Silty clay } \\
\text { (Fargo) }\end{array}$ \\
\hline Model 9 & Experiment 9 & Concave & Moderate & 0.060 & Loamy sand \\
\hline Model 10 & -- & Concave & Moderate & 0.15 & Loamy sand \\
\hline
\end{tabular}




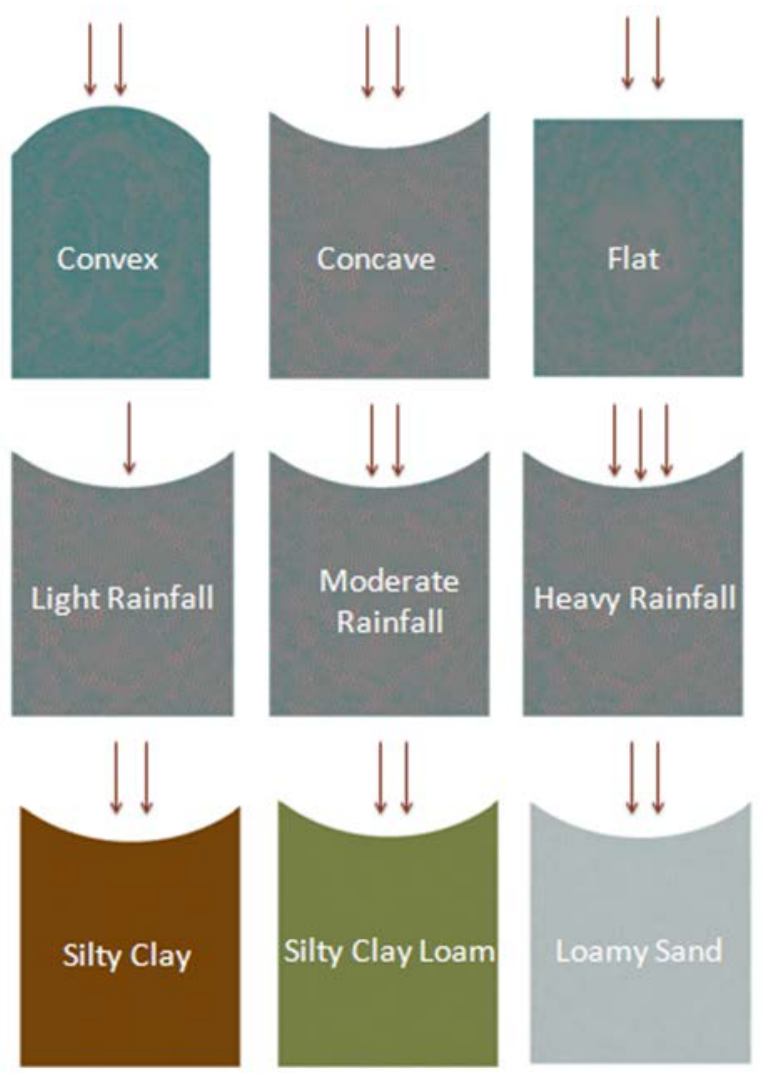

Fig. 2.5. Design details for experiments and simulations.

The scenario of surface microtopography included three distinct topographic conditions: convex, concave, and flat soil surfaces, which involved Models 1 - 3 and Experiments 1 - 3. The scenario of rainfall intensity included light, moderate, and heavy rainfalls that were applied to the same concave surface, which involved Models 4 - 6 and Experiments 4 - 6. In the scenario of soil type, loamy sand, silty clay, and silty clay loam were selected with the same concave surface, which involved Models 7 - 10 and Experiments 7 - 9 (Table 2.4 and Fig. 2.5). The modeling conditions for Model 10 were the same as Model 9 except the initial moisture condition. In addition, there was no relevant experiment for Model 10.

All the models had the same aimed initial condition, which was equal to the initial moisture content (i.e., $0.150 \mathrm{~cm}^{3} / \mathrm{cm}^{3}$ ) except Model 9. Note that the actual initial moisture 
contents used in the modeling were slightly different from the designed one $\left(0.150 \mathrm{~cm}^{3} / \mathrm{cm}^{3}\right)$. The upper boundary condition for all models was constant flux, and the bottom boundary condition was free drainage even though water did not reach the bottom for all modeling cases. There was no flux through both sides of each sub-box.

For the scenario of surface microtopography, the soil type was silty clay from Buxton, ND. The intensity of the applied steady rainfall was $0.040 \mathrm{~cm} / \mathrm{min}$. The actual initial soil moisture contents used in the modeling were $0.170,0.144$, and $0.160 \mathrm{~cm}^{3} / \mathrm{cm}^{3}$ for the convex, concave, and flat surfaces, respectively (Table 2.4). The aimed bulk density was $1.050 \mathrm{~g} / \mathrm{cm}^{3}$.

The three different intensities of steady rainfall (light: $0.023 \mathrm{~cm} / \mathrm{min}$, moderate: 0.043 $\mathrm{cm} / \mathrm{min}$, and heavy: $0.086 \mathrm{~cm} / \mathrm{min}$ ) were utilized in the scenario of rainfall intensity. The soil type, bulk density, and the aimed initial soil moisture contents were the same as those used for the scenario of surface microtopography. The actual initial moisture contents used in the corresponding models were $0.130,0.150$, and $0.130 \mathrm{~cm}^{3} / \mathrm{cm}^{3}$ for the light, moderate, and heavy rainfall, respectively (Table 2.4).

The moderate rainfall was utilized for the modeling in the scenario of soil type. The aimed initial soil moisture content was $0.150 \mathrm{~cm}^{3} / \mathrm{cm}^{3}$ for both silty clay and silty clay loam. Note that the initial aimed moisture content had to be changed to $0.07 \mathrm{~cm}^{3} / \mathrm{cm}^{3}$ for the loamy sand soil because higher initial water content for this coarse soil could prevent one from observing the wetting front movement. The actual initial conditions used in the models were $0.136 \mathrm{~cm}^{3} / \mathrm{cm}^{3}$ for silty clay, $0.146 \mathrm{~cm}^{3} / \mathrm{cm}^{3}$ for silty clay loam, while $0.06 \mathrm{~cm}^{3} / \mathrm{cm}^{3}$ for loamy sand (Table 2.4). The concave soil surface was used for the scenarios of rainfall intensity and soil type. 


\subsection{Evaluation of Model Performance}

The goodness-of-fit of the models was evaluated by using three methods: overall relative error $(E R R)$, Nash-Sutcliffe model efficiency coefficient $(E)$, and root mean square error (RMSE). The overall relative error was adopted to characterize the fitness between the entire experimental wetting front data and all the simulated ones:

$$
E R R=\frac{\left|D_{O b s}-D_{S i m}\right|}{D_{O b s}} \times 100 \%
$$

in which $D_{O b s}$ is the sum of the observed wetting front depths over the duration; and $D_{\text {Sim }}$ is the sum of the simulated wetting front data.

The Nash-Sutcliffe model efficiency coefficient has been widely used for assessing model performance. The efficiency coefficient of 1 indicates a perfect match of the experimental observations and the simulated data. The Nash-Sutcliffe model efficiency coefficient is given by (Nash and Sutcliffe1970):

$$
E=1-\frac{\sum_{i=1}^{n}\left(D_{O b s, i}-D_{S i m, i}\right)^{2}}{\sum_{i=1}^{n}\left(D_{O b s, i}-\overline{D_{O b s}}\right)^{2}}
$$

where $D_{O b s, i}$ and $D_{S i m, i}$ are respectively the observed and the simulated wetting front depth at time step $i ; \overline{D_{O b s}}$ is the mean value of the observations; and $n$ is the total number of time steps.

The root mean squared error (RMSE) represents the standard deviation of the differences between experimental wetting front data and the simulated ones for this study. The root mean square error can be expressed as:

$$
R M S E=\sqrt{\frac{\sum_{i=1}^{n}\left(D_{O b s, i}-D_{S i m, i}\right)^{2}}{n}}
$$




\section{CHAPTER 3. RESULTS AND DISCUSSION}

The major objectives of this chapter are to 1) compare the observed and simulated wetting front depths for scenarios of surface microtopography, rainfall intensity, and soil type; 2) explore the effects of three different microtopographic surfaces (convex, flat, and concave) on infiltration and unsaturated flow, especially on wetting front movement under the same controlled conditions; and 3) evaluate how rainfall intensity and soil type affect the wetting front movement under the same surface microtopography. In the experiments, the wetting front movement was observed and recorded. The wetting front depths were recorded at $X=0,5,10$, 15, and $20 \mathrm{~cm}$ for the convex and concave surfaces, and at $\mathrm{X}=5$ and $13 \mathrm{~cm}$ for the flat surface. The simulated and observed wetting fronts were compared. The soil-water moving patterns under the influence of microtopography were revealed based on the two-dimensional HYDRUS simulations.

3.1. Scenario One: Soil Water Movement under Three Different Surfaces (Convex, Concave, and Flat)

\subsubsection{Distribution of experimental wetting fronts}

The experimental wetting front depths were recorded at 14 different time points with a time interval of 4 min for the three different microtopographic surfaces (i.e., convex, concave, and flat surfaces) and their distributions are separately shown in Figs 3.1 - 3.3. For the convex surface (Fig. 3.1), the wetting front is parallel to the convex surface when infiltration starts. As

the wetting front moves to the deeper soil, the convex-shaped wetting front is gradually flattened over time and the final wetting front tends to be horizontally leveled. Comparing with the wetting front at the early stage, the later-stage wetting front becomes flat and even. A similar 
changing pattern of wetting front movement can be observed for the concave surface (Fig. 3.2). The shape of the wetting front is initially the same as the topography of the concave surface. Later, this concave-shaped wetting front becomes more even and flat over time. The spatial variation (elevation differences between the marginal points and central points) of the final wetting fronts is approximately $1 \mathrm{~cm}$ for both convex and concave surfaces, whereas the original elevation variation of the convex/concave surface is $5 \mathrm{~cm}$ as designed. For the flat surface (Fig. 3.3), the wetting front remains the same as the flat surface topography during the entire experimental time period. There is no obvious change in the shape of the wetting front for the flat surface.

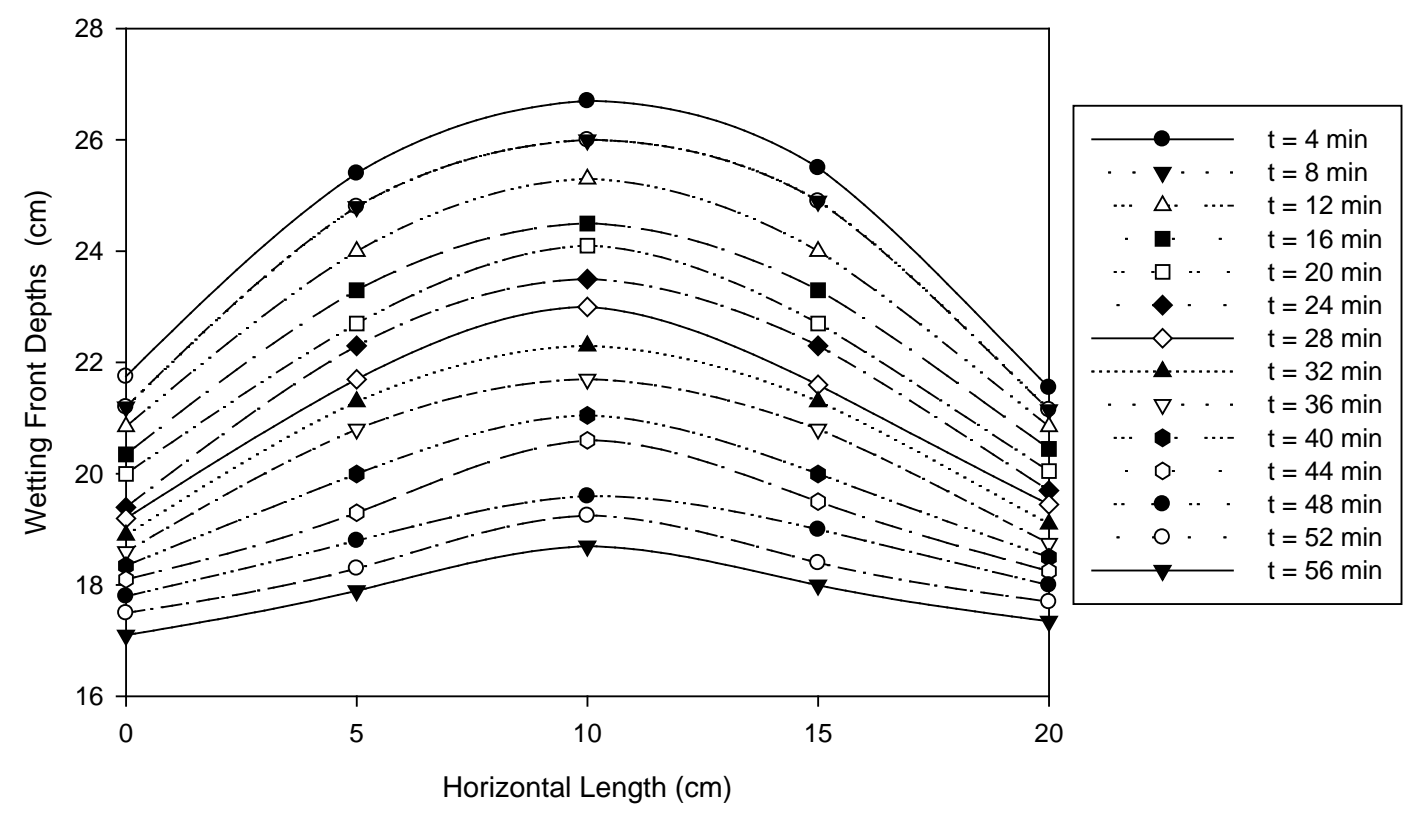

Fig. 3.1. Distribution of the experimental wetting fronts under the convex soil surface (rainfall $=$ $0.040 \mathrm{~cm} / \mathrm{min}$; duration = $56 \mathrm{~min}$; time interval $=4 \mathrm{~min}$ ). 


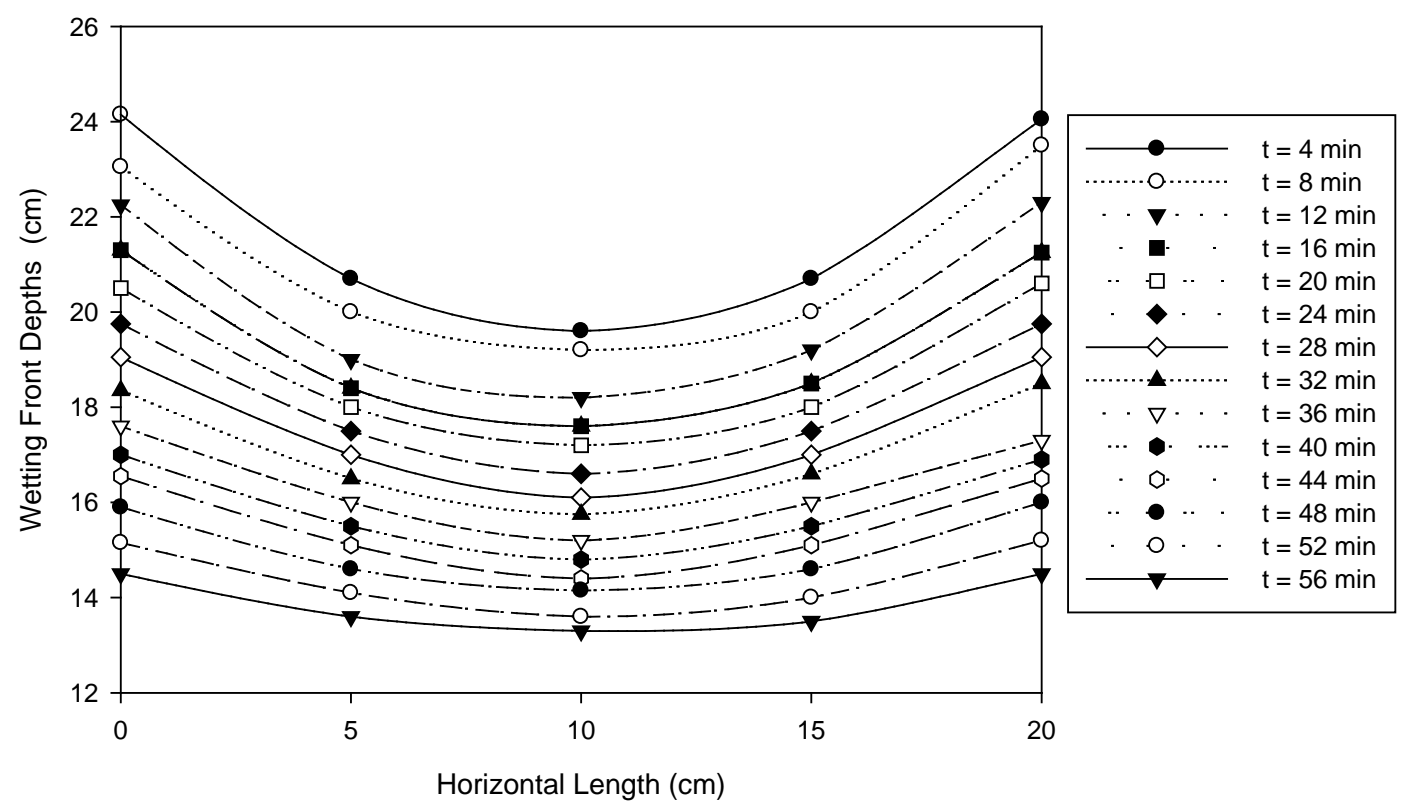

Fig. 3.2. Distribution of the experimental wetting fronts under the concave surface (rainfall intensity $=0.044 \mathrm{~cm} / \mathrm{min}$; duration $=56 \mathrm{~min}$; time interval $=4 \mathrm{~min}$ ).

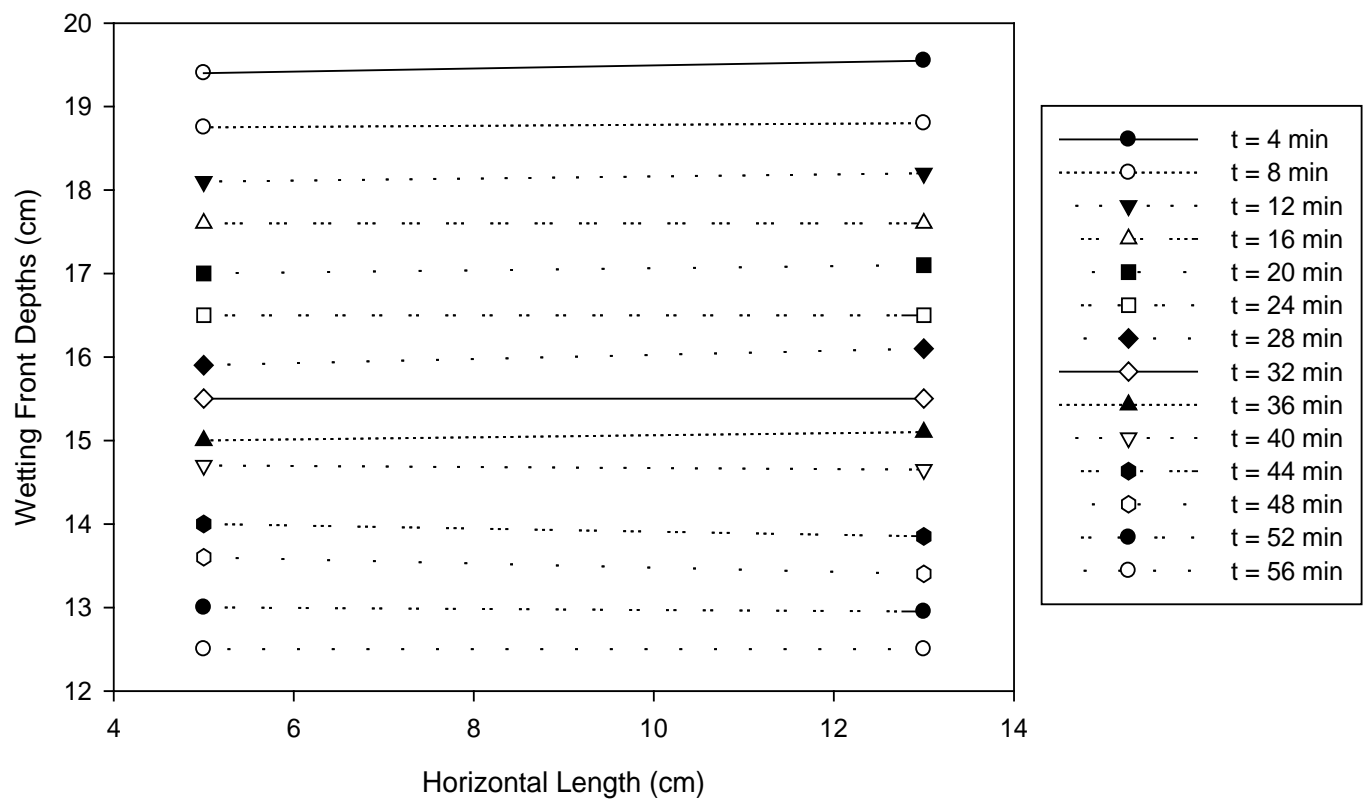

Fig. 3.3. Distribution of the experimental wetting fronts under the flat surface (rainfall intensity $=0.044 \mathrm{~cm} / \mathrm{min}$; duration $=56 \mathrm{~min}$; time interval $=4 \mathrm{~min})$. 
In summary, for the experiments associated with the convex and concave surfaces, the wetting front curves follow the shapes of the surface (i.e., surface microtopography) at the early stage, but gradually become flat in the horizontal direction. This can be attributed to the impact of lateral flow, which is driven by spatial differences in the matric potential caused by topography-influenced soil moisture non-uniformity.

\subsubsection{D HYDRUS modeling}

Three 2D HYDRUS models were developed to conceptually mimic the experiments for the three different surfaces (convex, concave, and flat). Each model was developed with the same surface topographic characteristics, initial and boundary conditions, and soil types as those in Experiments 1 - 3 (Table 2.4). Fig. 3.4 shows the simulated wetting front distributions at five time points ( $t=10,20,30,40$, and $50 \mathrm{~min})$ and the ending time point $(t=56 \mathrm{~min})$ for the three surfaces, and the simulated water content distributions along the soil profiles. The moving patterns of the wetting front and the changing patterns of the soil moisture content can be observed from Fig. 3.4.

For the convex and concave surfaces, the wetting front follows the shape of the surface microtopography at the early stage, and gradually becomes horizontally flat. The images in Fig. 3.4 indicate that the 2D soil-water flow effectively reduces the soil moisture differences in the horizontal direction over time. Such soil moisture differences are directly related to the spatial variations of surface microtopography. As a result, the wetting front eventually becomes flat and even (i.e., a horizontal plane) under the curved (convex and concave) microtopographic surfaces. During this process, horizontal flow plays an important role, and this importance will be further discussed in section 3.1.5. 


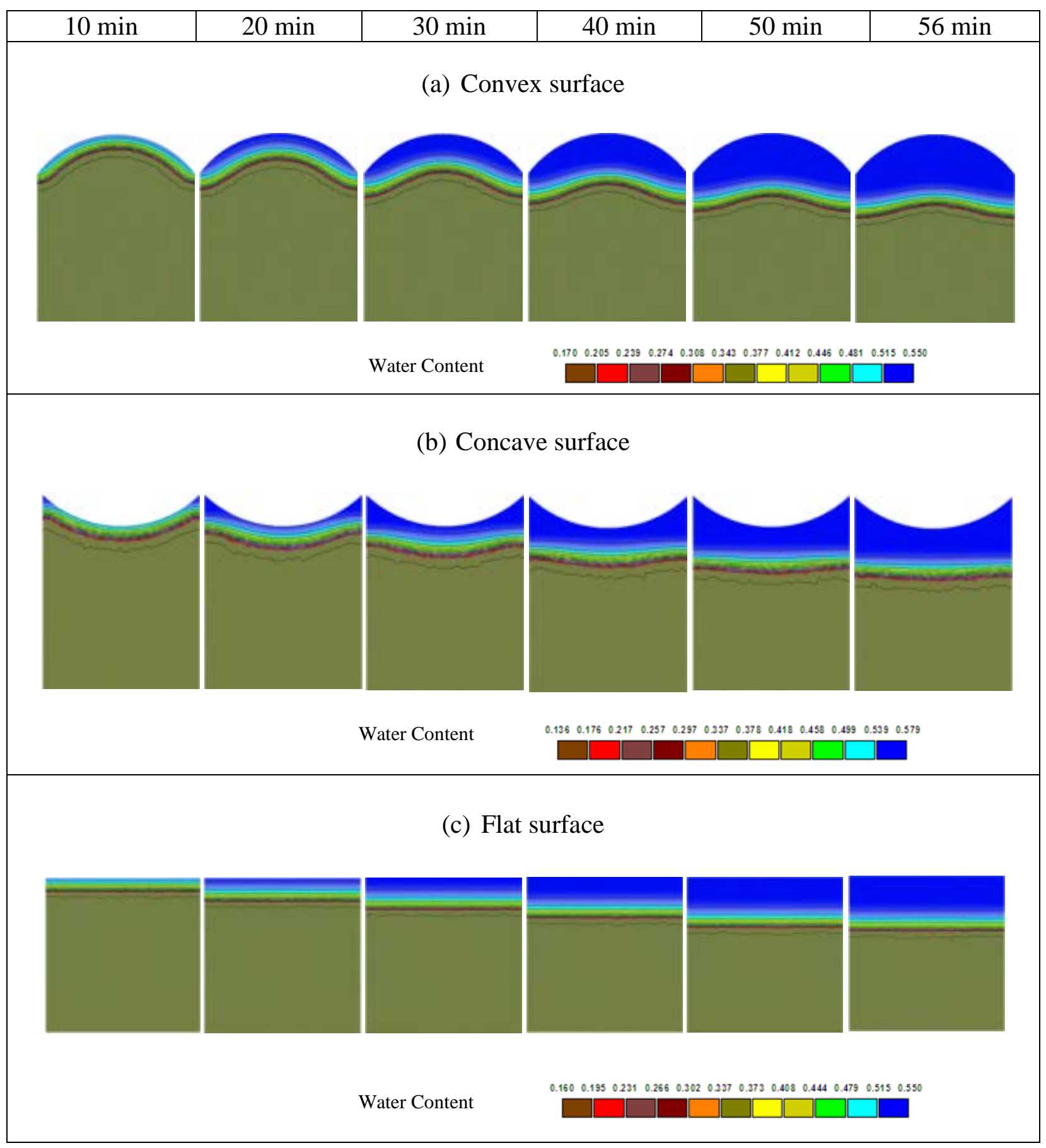

Fig. 3.4. Simulated wetting front movement and the distributions of soil water content for convex, concave, and flat surfaces at $\mathrm{t}=10,20,30,40,50$, and $56 \mathrm{~min}$. 
The influences of the curved surface microtopography on soil-water flow are getting weaker for deeper soil, which results in the horizontally flat wetting front (Fig. 3.4a - b). Different from the wetting front distributions of the curved surfaces (convex and concave); the wetting front under the flat surface moves downward uniformly (Fig. 3.4c) because there is no obvious spatial variation in surface microtopography. In addition, driven by the gravitational force, vertical flow dominates the wetting front movement under the flat surface (Fig. 3.4c). The distributions of the simulated water contents along the soil profiles of the three surfaces are shown in Fig. 3.5. Two locations (the horizontal distance $\mathrm{X}=5$ and $10 \mathrm{~cm}$, Figs. 3.1 - 3.3) on the soil surfaces were selected and represented by grey and red symbols, respectively (Fig. 3.5). For the convex surface (Fig. 3.5a), the surface elevation at $X=5 \mathrm{~cm}$ was $2.5 \mathrm{~cm}$, which was lower than that at $\mathrm{X}=10 \mathrm{~cm}$ within $10 \mathrm{~min}$. However, the soil moisture content at both locations gradually decreased along the soil column within 56 min. At the same time, the difference in the vertical distances between two equal-moisture points located at $X=5$ and 10 cm decreased over time as well. Similar results can be found for the concave surface (Fig. 3.5b). These modeling results match the observation in the laboratory experiments that the wetting front tended to gradually become flat, subsequently resulting in a leveled moving pattern of wetting front. However, no similar change is shown for the flat surface (Fig. 3.5c). Based on the current results, it can be concluded that the microtopographic influence was strong in shallow soil at the early stage, but decreased in deeper soil over time for both convex and concave surfaces. For the flat surface, the soil moisture contents at $X=5 \mathrm{~cm}$ matched those at $X=10 \mathrm{~cm}$. Unlike the two curved soil surfaces, the flat soil surface was featured with uniformly distributed soil moisture content and wetting front movement during the whole process. 

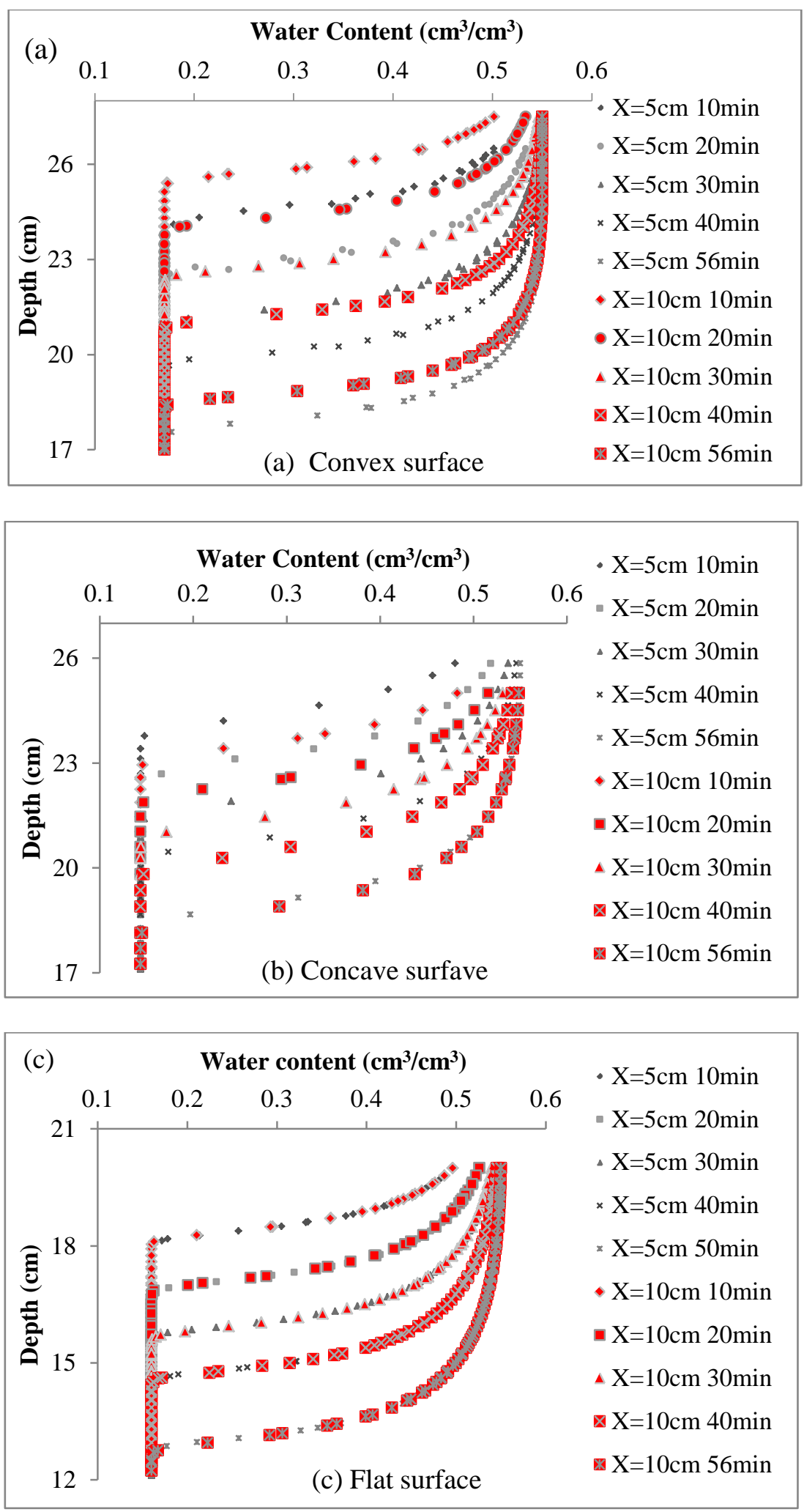

Fig. 3.5. Simulated water content distributions along soil depth at $X=5$ and $10 \mathrm{~cm}$ for the convex, concave, and flat surfaces. 


\subsubsection{Comparison between the observed and simulated wetting front data}

The performance of the three models was evaluated by comparing the observed and simulated wetting fronts. The comparisons of the observed and simulated wetting front depths for the convex, concave, and flat surfaces are exhibited in Figs. 3.6a - c, respectively. For the convex and flat surfaces, the data points are distributed closely along the 1:1 line, indicating that the simulation results are very close to the corresponding experimental wetting fronts. For the concave surface, some data points are scatted away from the 1:1 line, indicating certain discrepancy in these two data sets.
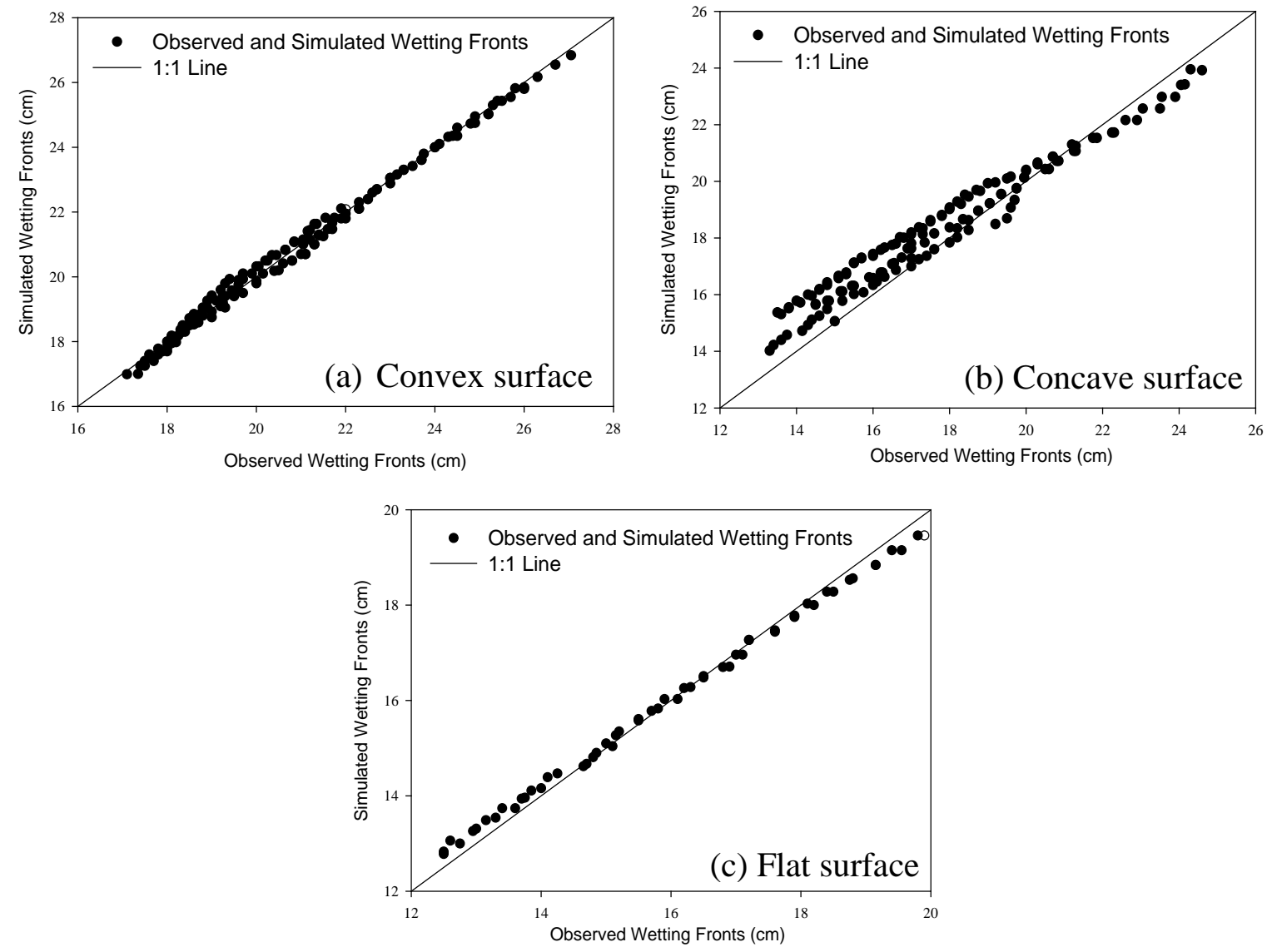

Fig. 3.6. Comparisons of the observed and simulated wetting front depths for the convex, concave, and flat surfaces. 
In addition, statistical analysis has been conducted to evaluate the performance of the three models. Table 3.1 shows the overall relative error (ERR), the Nash-Sutcliffe model efficiency coefficient (E), and the root mean squared error (RMSE) for the three surfaces. The overall relative errors of the simulated wetting front depths are $0.769 \%$, $4.558 \%$, and $1.137 \%$ for the convex, concave, and flat surfaces, respectively (Table 3.1). The Nash-Sutcliffe model efficiency coefficient values are $0.994,0.893$, and 0.990 for the convex, concave, and flat surfaces, respectively, suggesting good agreement between the simulated and observed data (note that the efficiency coefficient of 1 indicates a perfect match). The performance of the model for the convex surface is better than two others. Thus, the three HYDRUS 2D models are able to provide reasonable simulations of unsaturated flow and wetting front movement, which help better understand the related physical processes.

Table 3.1. Quantitative evaluation of the model performance for the three surfaces

\begin{tabular}{|c|c|c|c|}
\hline & Convex surface & Concave surface & Flat surface \\
\hline ERR & $0.769 \%$ & $4.558 \%$ & $1.137 \%$ \\
\hline E & 0.994 & 0.893 & 0.990 \\
\hline RMSE & 0.194 & 0.899 & 0.210 \\
\hline
\end{tabular}

\subsubsection{Microtopographic effects on soil-water movement}

Both laboratory experiments and the corresponding models revealed that the wetting front tended to become even and flat although it initially retained the surface microtopographic shape featuring peaks and depressions. This tendency can be directly verified by the standard deviation calculated from the collected wetting front depth data. A smaller standard deviation value implies that the spatial distribution of wetting front is more uniform while a greater value indicates a wide range of distributions of wetting front depths (i.e., a strongly curved wetting front). 
Fig. 3.7 illustrates that when infiltration starts, the elevation difference of the wetting front depths between the edge and the center (the difference between the edge and the peak/depression for the convex/concave surface) decreases. The decreased standard deviations for both convex and concave surfaces suggest that the curved wetting front is leveled off over time. Consequently, a flat wetting front is progressively formed. This conclusion is consistent with the finding from the experiments and modeling that the microtopographic influence is strong at the beginning but decreases over time. Thus, wetting front movement is strongly affected by the variations of surface microtopography and the soil matric forces at the early stage. After a certain time, gravity dominates the soil-water movement, which results in a leveled wetting front. In this study, the influence of the microtopography of the convex surface is slightly stronger than that of the concave surface because the standard deviation for convex surface is slightly greater than that of the concave surface (Fig. 3.7). For the flat surface, since the wetting front is flat for all time steps, only minor variations in the standard deviation can be observed (Fig. 3.7).

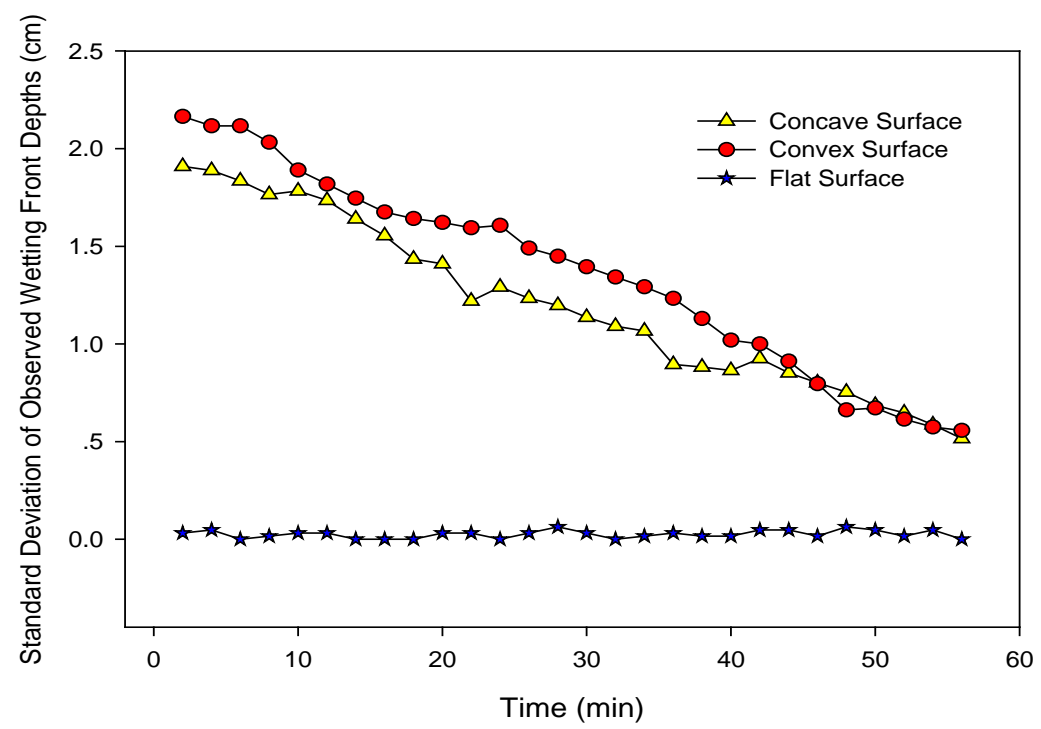

Fig. 3.7. Temporal distributions of standard deviations of the observed wetting front depths for convex, concave, and flat surfaces. 
Table 3.2 shows the comparison of the wetting front depths for all three experiments. The data were selected at $\mathrm{t}=20,40$, and $56 \mathrm{~min}$. For the wetting front depths at the central points (at the peak/depression for convex/concave), the convex surface has the greatest wetting front depths for the three selected times. In contrast, the wetting front at the marginal points (at the two edges) underneath the concave surface is the deepest at the selected times (Table 3.2). The central wetting front depths underneath the flat surface are close to the ones under the concave surface. However, the average wetting front depths of the concave surface are greater than those of the flat surface within a longer duration (Table 3.2). The greatest average wetting front depths imply that the wetting front under the concave surface moves slightly faster than the ones under the two other surfaces (Table 3.2).

Table 3.2. Comparison of wetting front depths for the three microtopographic surfaces at three selected times

\begin{tabular}{|c|c|c|c|}
\hline Time (min) & $\begin{array}{l}\text { Wetting front depths } \\
\text { underneath the } \\
\text { convex surface }(\mathrm{cm})\end{array}$ & $\begin{array}{l}\text { Wetting front depths } \\
\text { underneath the } \\
\text { concave surface }(\mathrm{cm})\end{array}$ & $\begin{array}{l}\text { Wetting front depths } \\
\text { underneath the flat } \\
\text { surface }(\mathrm{cm})\end{array}$ \\
\hline \multicolumn{4}{|c|}{ Wetting front depths at the central points } \\
\hline 20 & 3.40 & 2.80 & 2.90 \\
\hline 40 & 6.45 & 5.20 & 5.30 \\
\hline 56 & 8.80 & 6.70 & 7.50 \\
\hline \multicolumn{4}{|c|}{ Wetting front depths at the marginal points } \\
\hline 20 & 2.47 & 4.45 & 2.90 \\
\hline 40 & 4.07 & 8.05 & 5.30 \\
\hline 56 & 5.27 & 10.50 & 7.50 \\
\hline \multicolumn{4}{|c|}{ Average wetting front depths } \\
\hline 20 & 2.94 & 3.63 & 2.90 \\
\hline 40 & 5.26 & 6.63 & 5.30 \\
\hline 56 & 7.04 & 8.60 & 7.50 \\
\hline
\end{tabular}

Significant differences in the wetting front depths under the flat and convex surfaces can be observed for the central and margin points, but their average wetting front depths, especially 
at the early stage, are surprisingly similar (Table 3.2). Among all the three surfaces, the concave surface has a deeper average wetting front, which can be attributed to its faster movement underneath the marginal points. But the wetting front of the concave surface moves slightly slower beneath the central points (Table 3.2).

\subsubsection{Discussion on the changing pattern of wetting front movement}

During the process of infiltration and soil-water percolation, wetting front followed the shape of the surface microtopography at the early stage, and gradually became leveled. The curvature of the concave/convex surface was equal to that of the initial wetting front when infiltration started. After subsequent infiltration into the soil, the curvature of the wetting front gradually decreased. At the final stage, a flat wetting front formed.

To better understand this tendency of wetting front movement, the simulated water velocity vectors are used to show the soil-water flow directions under different microtopographic conditions (Fig. 3.8). As shown in Fig. 3.8a, soil water moves away from the center of the concave surface, forming a divergent pathway. In contrast, a convergent flow pathway is formed under the convex surface (Fig. 3.8b). This radial moving direction of soil water implies a strong unsaturated flow in the horizontal direction controlled by soil matric forces. The larger the radian is; the more soil water moves horizontally. That is, greater spatial variations in surface elevations induce stronger horizontal flow, which leads to a leveled moving pattern of wetting front. The soil-water flow and its directions are essentially driven by gravitational force and soil matric forces. 


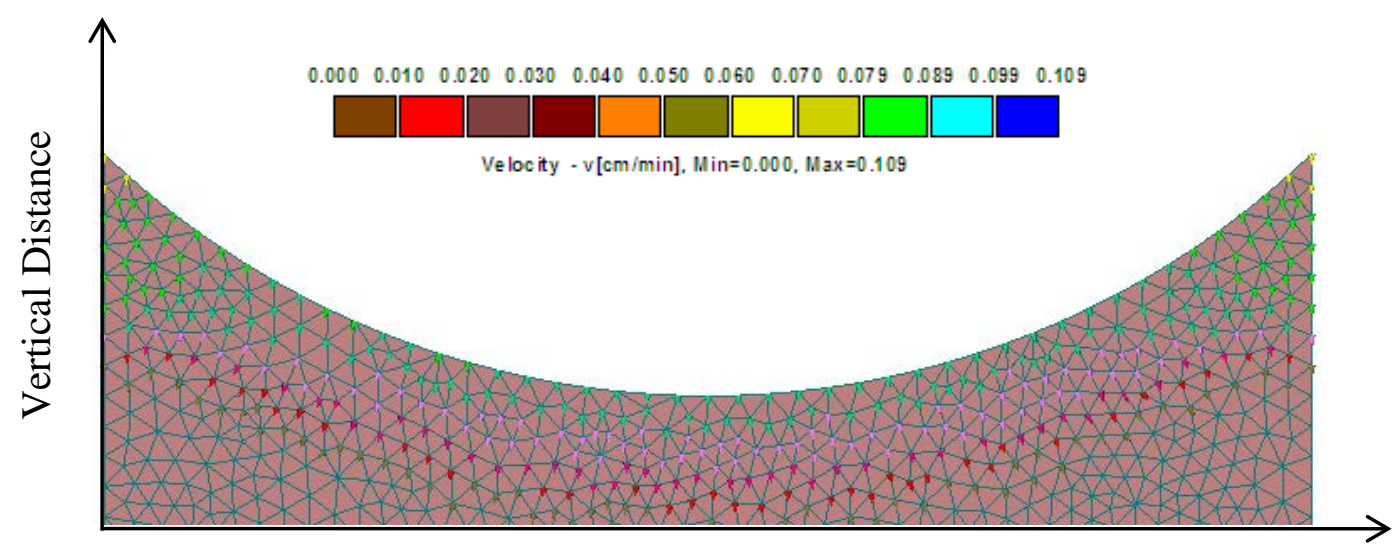

Horizontal Distance

(a) Concave surface

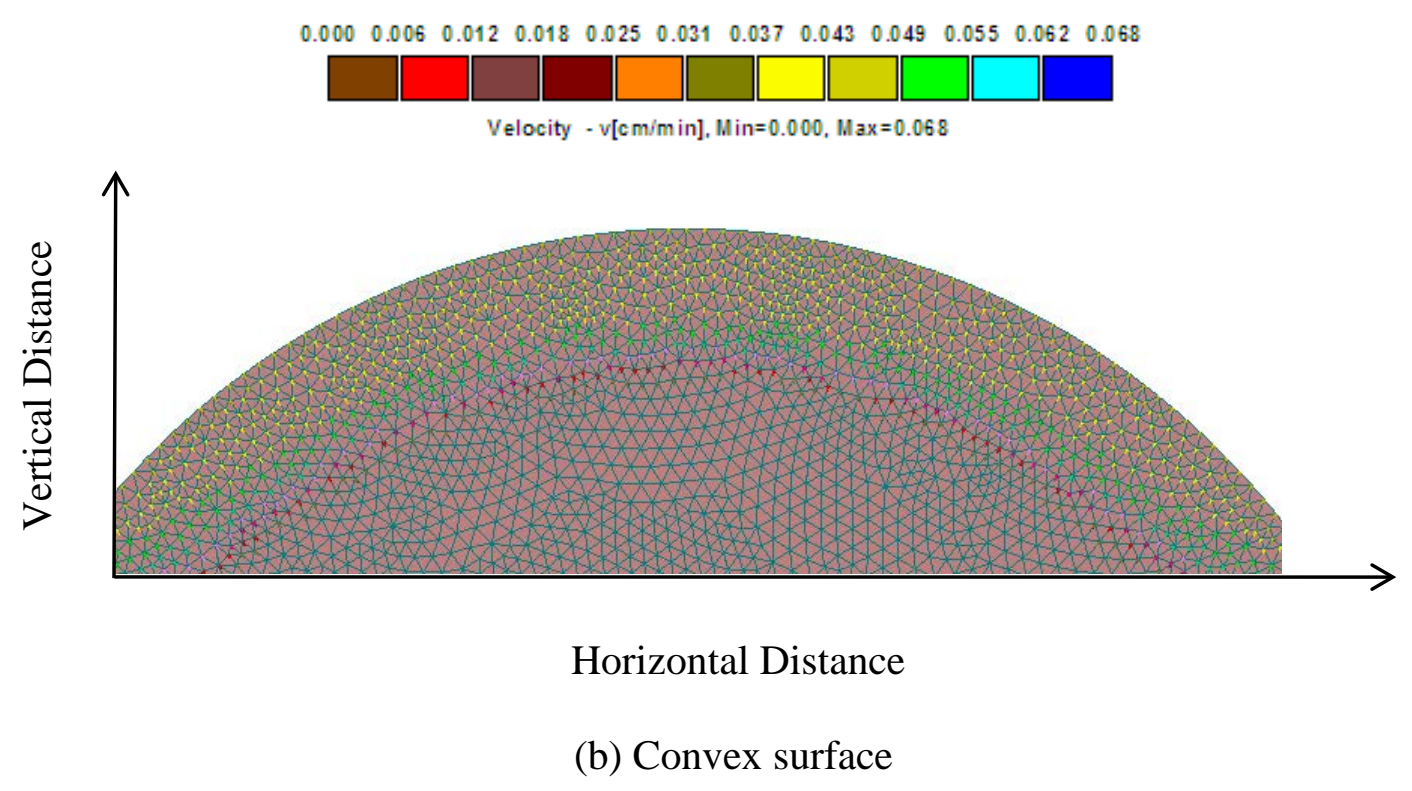

Fig. 3.8. Soil-water flow directions for the concave and convex surfaces.

Therefore, at the early stage, soil matric forces drove soil water to move towards adjacent drier soil, and thus played a more significant role in governing the unsaturated flow under a curved surface with non-uniformly distributed soil moisture contents. This resulted in a flat and even wetting front at the final stage. Hence, a surface with greater topographic variations (a 
rougher surface) needs more time to balance the difference of soil moisture in the horizontal direction.

\subsection{Scenario Two: Soil Water Movement under Three Different Rainfall Intensities}

3.2.1. Experimental wetting front movement under three different steady rainfall intensities

In the scenario of rainfall intensity, the concave soil surface was used for all three soil columns. Figs. 3.9 - 3.11 respectively display the distributions of the experimental wetting fronts for the light, moderate, and heavy rainfall events. The wetting front depths were recorded at $\mathrm{X}$ $=0,2.5,10,17.5$, and $20 \mathrm{~cm}$ for a series of time points. Selection of the rainfall intensities ensured that the impact of rainfall on surface microtopography was minimal. Therefore, the raindrop effects can be negligible in this study.

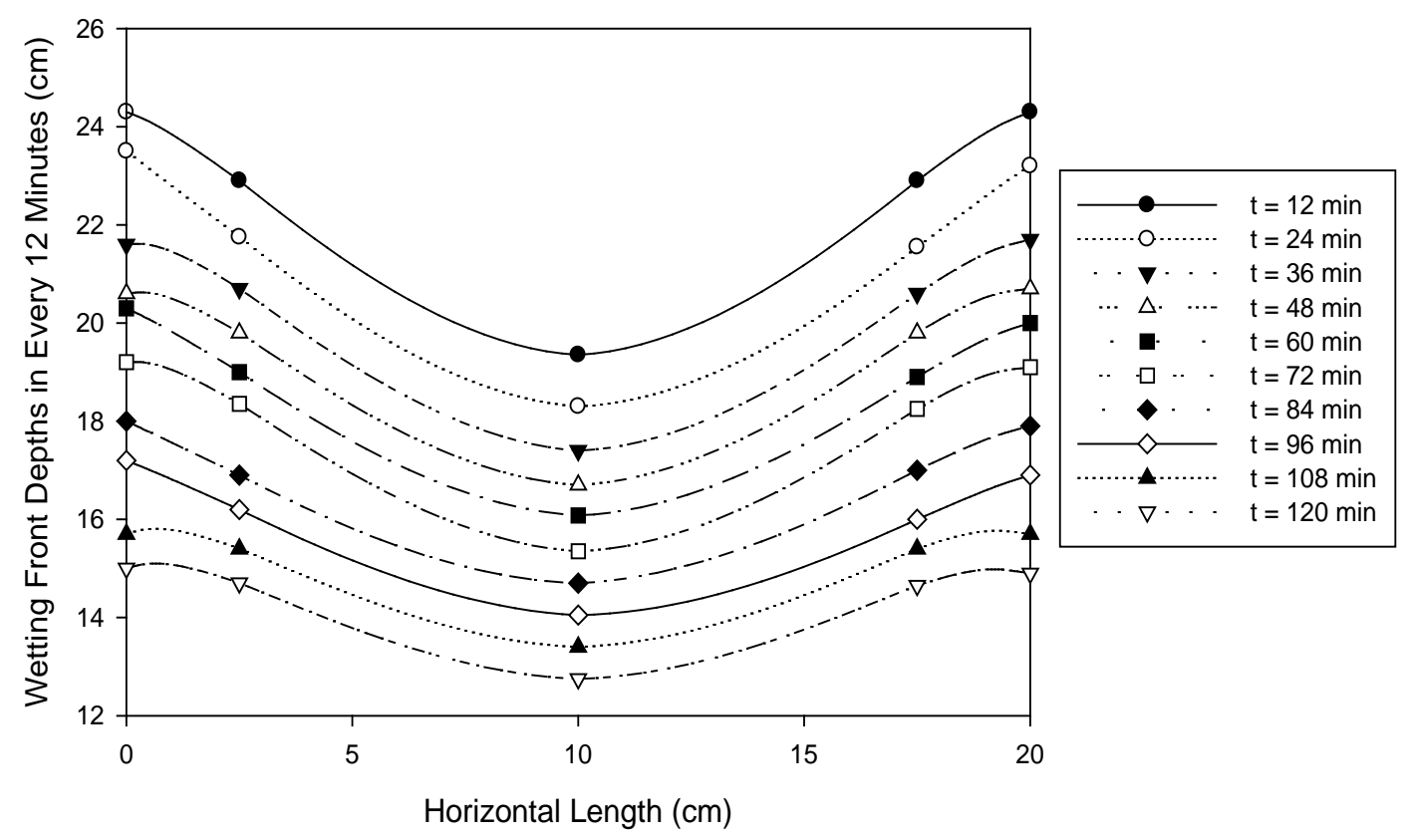

Fig. 3.9. Distribution of the experimental wetting fronts for light rainfall (intensity $=0.023$ $\mathrm{cm} / \mathrm{min}$; time interval $=12 \mathrm{~min}$; duration $=120 \mathrm{~min}$. 


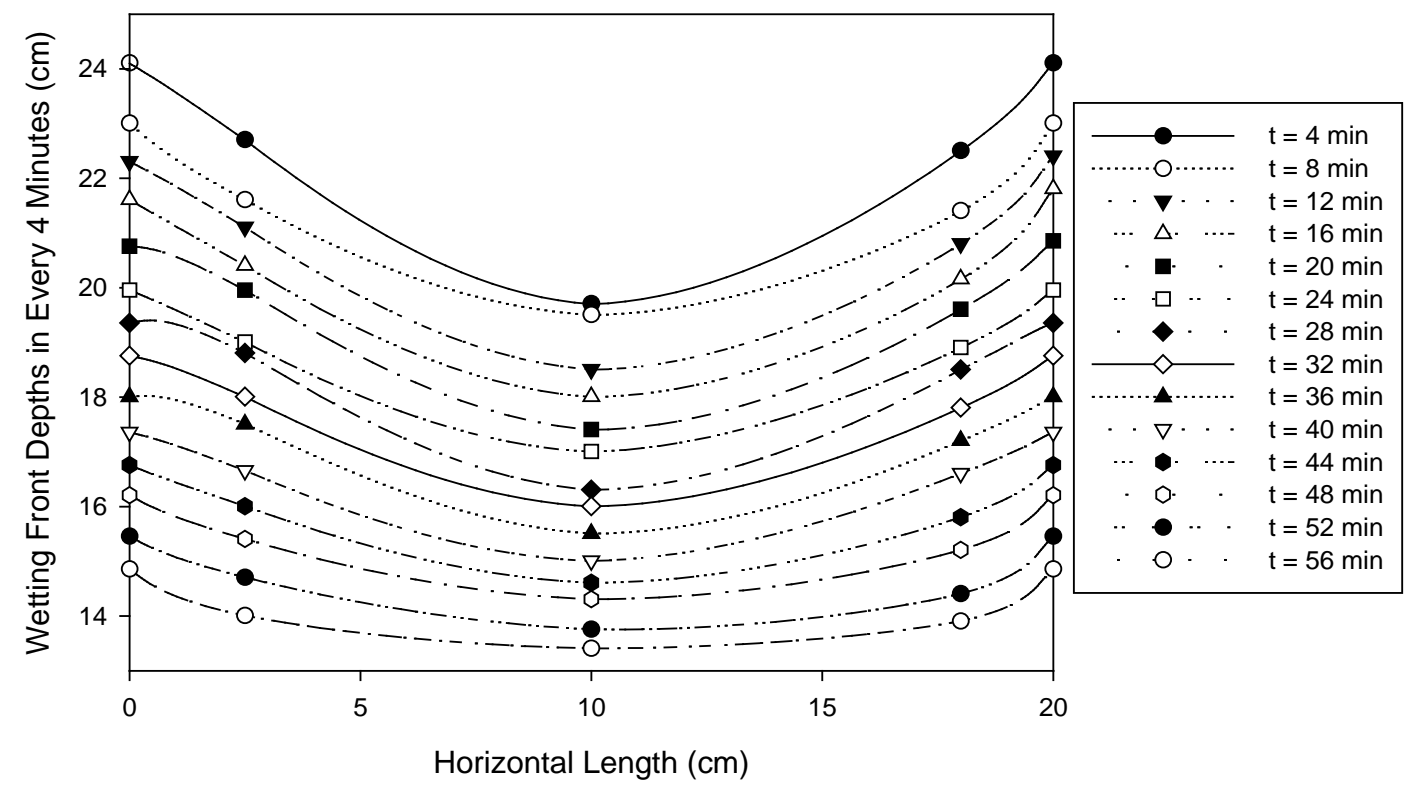

Fig. 3.10. Distribution of the experimental wetting fronts for moderate rainfall (intensity $=0.043$ $\mathrm{cm} / \mathrm{min}$; time interval $=4 \mathrm{~min}$; duration $=56 \mathrm{~min})$.

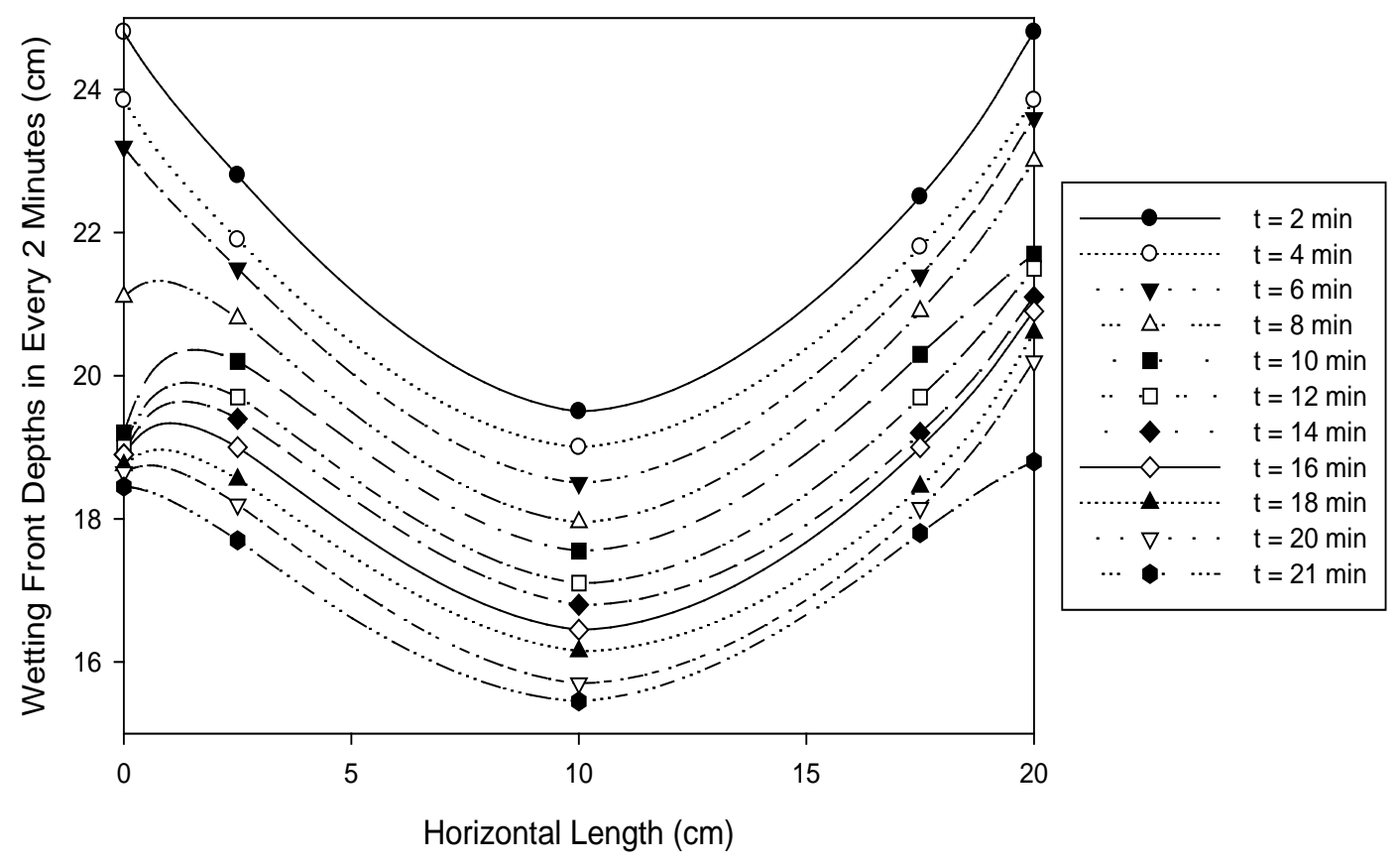

Fig. 3.11. Distribution of the experimental wetting fronts for heavy rainfall (intensity $=0.086$ $\mathrm{cm} / \mathrm{min}$; time interval = $2 \mathrm{~min}$; duration $=21 \mathrm{~min}$ ). 
A similar trend of wetting front movement can be observed for the three rainfall conditions (Figs. 3.9 - 3.11). The moving patterns of wetting front tended to become even and flat when the wetting front moved downwards. This phenomenon was clearly shown for the light and moderate rainfall events (Figs. 3.9 and 3.10). For the heavy rainfall event, however, wetting front movement did not evidently exhibit this tendency due to the faster occurrence of ponding condition (Fig. 3.11). The circle in Fig. 3.11 indicates some unexpected errors from the experiment. It was possibly caused by the non-uniformity in soil hydraulic properties and moisture distributions in the areas close to the soil box boundaries during soil packing.

As shown in Figs. 3.9 - 3.11, the difference of the final wetting front depths between the edge point $(\mathrm{X}=20 \mathrm{~cm})$ and the central point $(\mathrm{X}=10 \mathrm{~cm})$ is much smaller than the one at the beginning. The vertical elevation difference reduces from $5.0 \mathrm{~cm}$ to $3.5 \mathrm{~cm}$ for the final wetting front under the heavy rainfall (Fig. 3.11). Based on visual comparison, the curvature of the final wetting front in the deepest soil under the moderate rainfall is smaller than that of the light rainfall. This means that the final wetting front under the moderate rainfall is more uniformly distributed than the one under the light rainfall, even though the duration of the moderate rainfall (56 min) is shorter than that of the light rainfall (120 min). Thus, rainfall intensity plays an important role in the formation of the leveled wetting front distribution.

\subsubsection{Comparison between the observed and simulated wetting fronts}

HYDRUS 2D modeling was conducted for the three rainfall events (light, moderate, and heavy). The performance of the modeling was evaluated by comparing the observed and simulated wetting fronts. Figs. 3.12a - c respectively illustrate the comparisons of the observed and simulated wetting front data for the three selected rainfall events. It can be seen from Fig. 
3.12 that both observed and simulated wetting fronts are closely scattered along the 1:1 line for the light and moderate rainfall events. The simulated wetting front data matched the observed ones for these two rainfall events, indicating a better performance of the corresponding HYDRUS 2D models. For the heavy rainfall, however, the model underestimated the wetting front depths, which probably can be attributed to certain unexpected errors in the experiments as mentioned before.
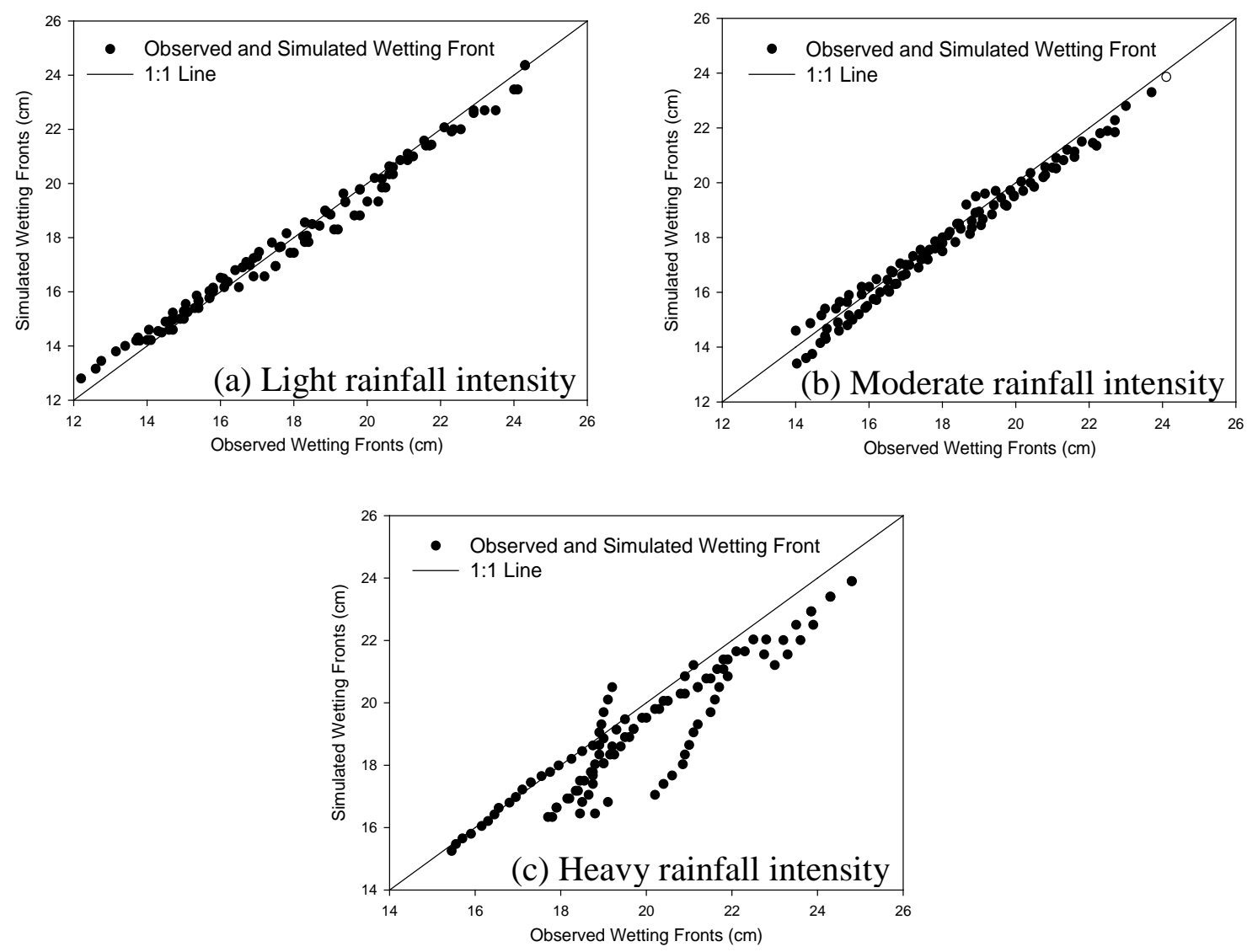

Fig. 3.12. Comparison of observed and simulated wetting fronts for light rainfall (intensity = $0.023 \mathrm{~cm} / \mathrm{min}$ ), moderate rainfall (intensity $=0.043 \mathrm{~cm} / \mathrm{min}$ ), and heavy rainfall (intensity = $0.086 \mathrm{~cm} / \mathrm{min})$.

Table 3.3 shows the statistical analysis results of the model performance for the three rainfall events. The overall relative errors (ERR) of the simulated wetting front depths are 
1.890\%, 2.038\%, and 4.395\% for the light, moderate, and heavy rainfall, respectively (Table 3.3). The calculated Nash-Sutcliffe model efficiency coefficients (E) in Table 3.3 indicate that all the three models provide good results, and the modeling for the light rainfall is the best. This implies that the heavier the rainfall is, the less accurate the model might be. The values of the root mean squared error RMSE for the light, moderate, and heavy rainfall events are $0.404,0.415$, and 1.152, respectively. The values of RMSE for the scenario of rainfall intensity are greater than those in the scenario of surface microtopography. In general, good agreement between the experimental observation and the simulated wetting fronts has been achieved.

Table 3.3. Quantitative evaluation of the model performance for the three rainfall events

\begin{tabular}{|c|c|c|c|}
\hline & Light rainfall & Moderate rainfall & Heavy rainfall \\
\hline ERR & $1.890 \%$ & $2.038 \%$ & $4.395 \%$ \\
\hline E & 0.982 & 0.972 & 0.890 \\
\hline RMSE & 0.404 & 0.415 & 1.152 \\
\hline
\end{tabular}

\subsubsection{Effects of rainfall intensity on topography-influenced wetting front movement}

The wetting front under the concave surface was first parallel to the curved surface, but progressively became even and flat. The data from the experiments for the light and moderate rainfall events evidently showed this tendency, which partially can be attributed to their longer durations. To better illustrate the changing rates of forming the leveled wetting front affected by different rainfall intensities, the relationship between time ( $\mathrm{t}$ ) and the standard deviation (SD) of wetting front depths was determined.

Fig 3.13 shows the standard deviation of the observed wetting front depths between the central and marginal points at all time steps. For the three rainfall intensities, standard deviation decreases with time (Fig. 3.13). Note that when standard deviation is zero, an even and flat 
wetting front distribution is formed. In summary, rainfall intensity affects the timing that the wetting front reaches the horizontally uniform stage.

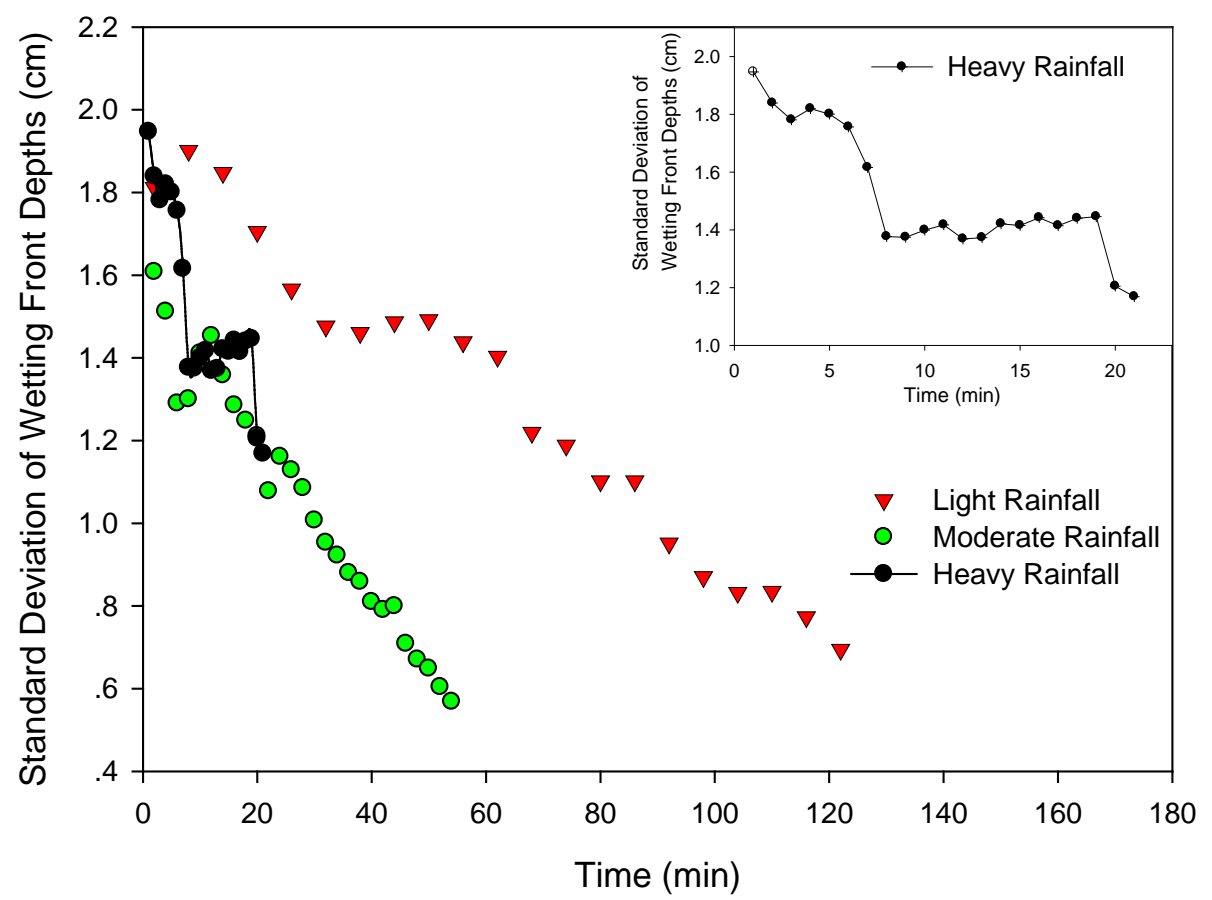

Fig. 3.13. Temporal distributions of the standard deviation of the observed wetting front for light, moderate, and heavy rainfall events.

Based on the calculated standard deviation in Fig. 3.13, a regression equation was fitted for each set of the observed wetting front data. Table 3.4 lists the linear regression equations for the light, moderate, and heavy rainfall events. The gradients of the regression equations show how rainfall intensity impacts the timing of the leveled wetting front distribution. The gradient for the moderate rainfall (0.0184) is almost twice greater than that of the light rainfall (0.0099) (Table 3.4). Similarly, the slope for the heavy rainfall is much greater than that of the moderate rainfall. Thus, the timing of the leveled wetting front distribution is strongly controlled by the rainfall intensity. Heavier rainfall tends to expedite the formation of the uniformly distributed wetting front. 
Table 3.4. Regression equations of standard deviations of wetting front depths (SD) vs. time (t) for light, moderate, and heavy rainfall events

\begin{tabular}{|c|c|c|c|}
\hline & $\begin{array}{c}\text { Light Rainfall } \\
(0.023 \mathrm{~cm} / \mathrm{min})\end{array}$ & $\begin{array}{c}\text { Moderate Rainfall } \\
(0.043 \mathrm{~cm} / \mathrm{min})\end{array}$ & $\begin{array}{c}\text { Heavy Rainfall } \\
(0.086 \mathrm{~cm} / \mathrm{min})\end{array}$ \\
\hline $\begin{array}{c}\text { Linear } \\
\text { Regression }\end{array}$ & $\mathrm{SD}=-0.0099 \mathrm{t}+1.91$ & $\mathrm{SD}=-0.0184 \mathrm{t}+1.57$ & $\mathrm{SD}=-0.0304 \mathrm{t}+1.85$ \\
\hline
\end{tabular}

Table 3.5 shows the wetting front depths at different locations for $\mathrm{t}=20 \mathrm{~min}$. It can be observed that the heavier the rainfall is, the deeper the wetting front is at the same time step for both central and marginal points. The pertinent standard deviation values are 1.70, 1.22, and 1.20 for the light, moderate, and heavy rainfall events, respectively (Table 3.5). Although the wetting front moved fastest under the heavy rainfall, it took the least time for the wetting front to become uniformly distributed. Hence, heavier rainfall intensity leads to faster wetting front movement, and it takes less time for a curved wetting front to be leveled under a rough topographic surface.

Table 3.5. Selected wetting front depths for the three rainfall events at $\mathrm{t}=20 \mathrm{~min}$

\begin{tabular}{|c|c|c|c|}
\hline Locations & $\begin{array}{c}\text { Light Rainfall } \\
(0.023 \mathrm{~cm} / \mathrm{min})\end{array}$ & $\begin{array}{c}\text { Moderate Rainfall } \\
(0.043 \mathrm{~cm} / \mathrm{min})\end{array}$ & $\begin{array}{c}\text { Heavy Rainfall } \\
(0.086 \mathrm{~cm} / \mathrm{min})\end{array}$ \\
\hline $\begin{array}{c}\text { Depth at Central } \\
\text { Points (cm) }\end{array}$ & 2.200 & 2.800 & 4.450 \\
\hline $\begin{array}{c}\text { Depth at Marginal } \\
\text { Points (cm) }\end{array}$ & 2.550 & 4.500 & 6.500 \\
\hline Average Depth (cm) & 2.375 & 3.650 & 5.475 \\
\hline $\begin{array}{c}\text { Standard Deviation } \\
(\mathrm{cm})\end{array}$ & 1.700 & 1.220 & 1.200 \\
\hline
\end{tabular}

\subsection{Scenario Three: Water Movement in Three Different Types of Soil}

In this scenario, three types of soil (loamy sand, silty clay, and silty clay loam) were used and the concave surface was selected. The moderate rainfall (intensity $=0.044 \mathrm{~cm} / \mathrm{min}$ ) was applied to all the three types of soil. No ponding condition was considered in this scenario. The wetting front depths were recorded at horizontal distance $X=0,2.3,10,17.7$, and $20 \mathrm{~cm}$. 


\subsubsection{Distribution of experimental wetting front movement within three types of soil}

The experimental durations are 20, 30, and 56 min for the silty clay loam, silty clay, and loamy sand, respectively. The target initial moisture content for both silty clay loam and silty clay is $0.150 \mathrm{~cm}^{3} / \mathrm{cm}^{3} .0 .070 \mathrm{~cm}^{3} / \mathrm{cm}^{3}$ is selected for loamy sand because $15 \%$ of soil moisture makes observation of wetting front difficult. The observed wetting fronts for the silty clay loam, silty clay, and loamy sand are respectively displayed in Figs 3.14 - 3.16. Due to the shorter durations for silty clay loam and silty clay, the final wetting fronts for both cases do not evidently show a uniform, flat distribution (Figs. 3.14 and 3.15) before the ponding condition. However, the wetting front of the loamy sand soil (Fig. 3.16) shows a leveled wetting front distribution distinctly appeared in the deeper soil.

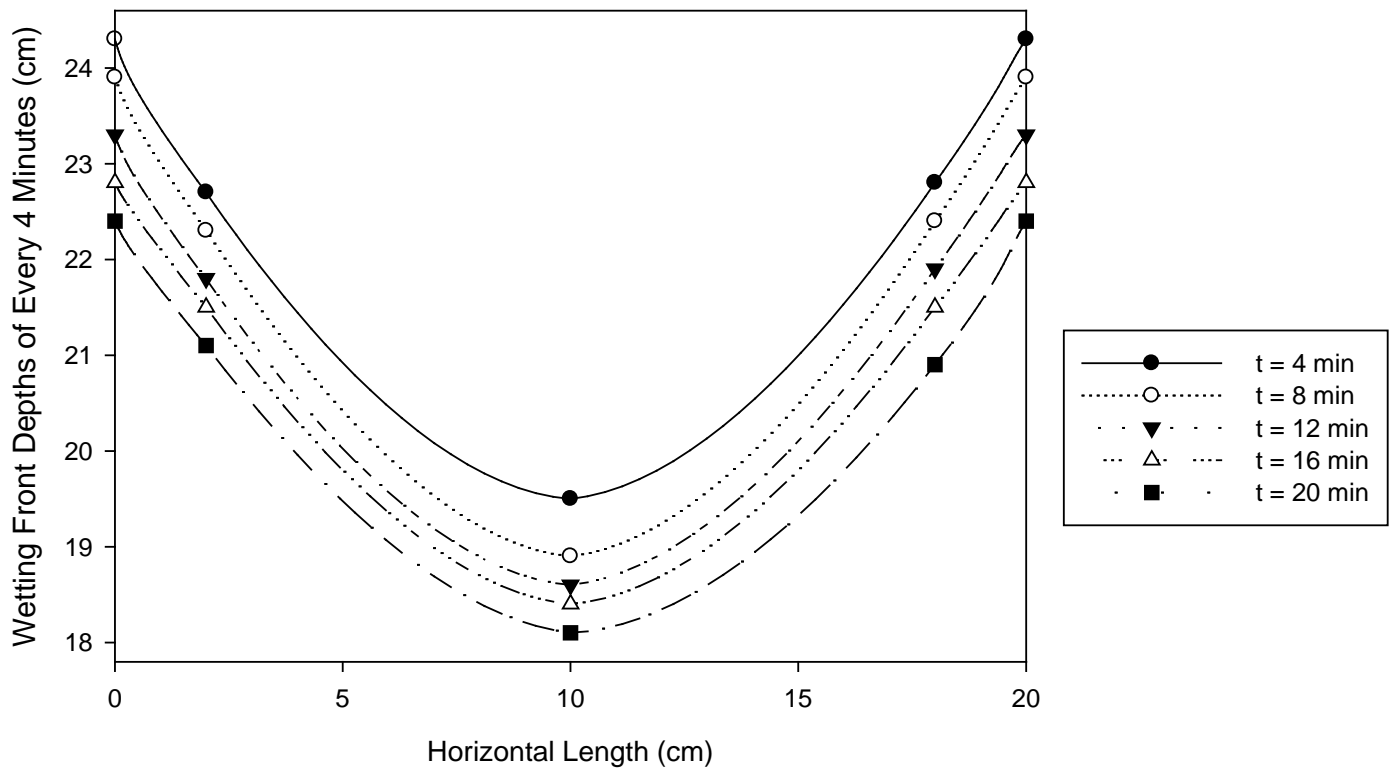

Fig. 3.14. Distribution of the experimental wetting fronts for silty clay loam soil (rainfall intensity $=0.044 \mathrm{~cm} / \mathrm{min}$; time interval $=4 \mathrm{~min}$; duration $=20 \mathrm{~min}$ ). 


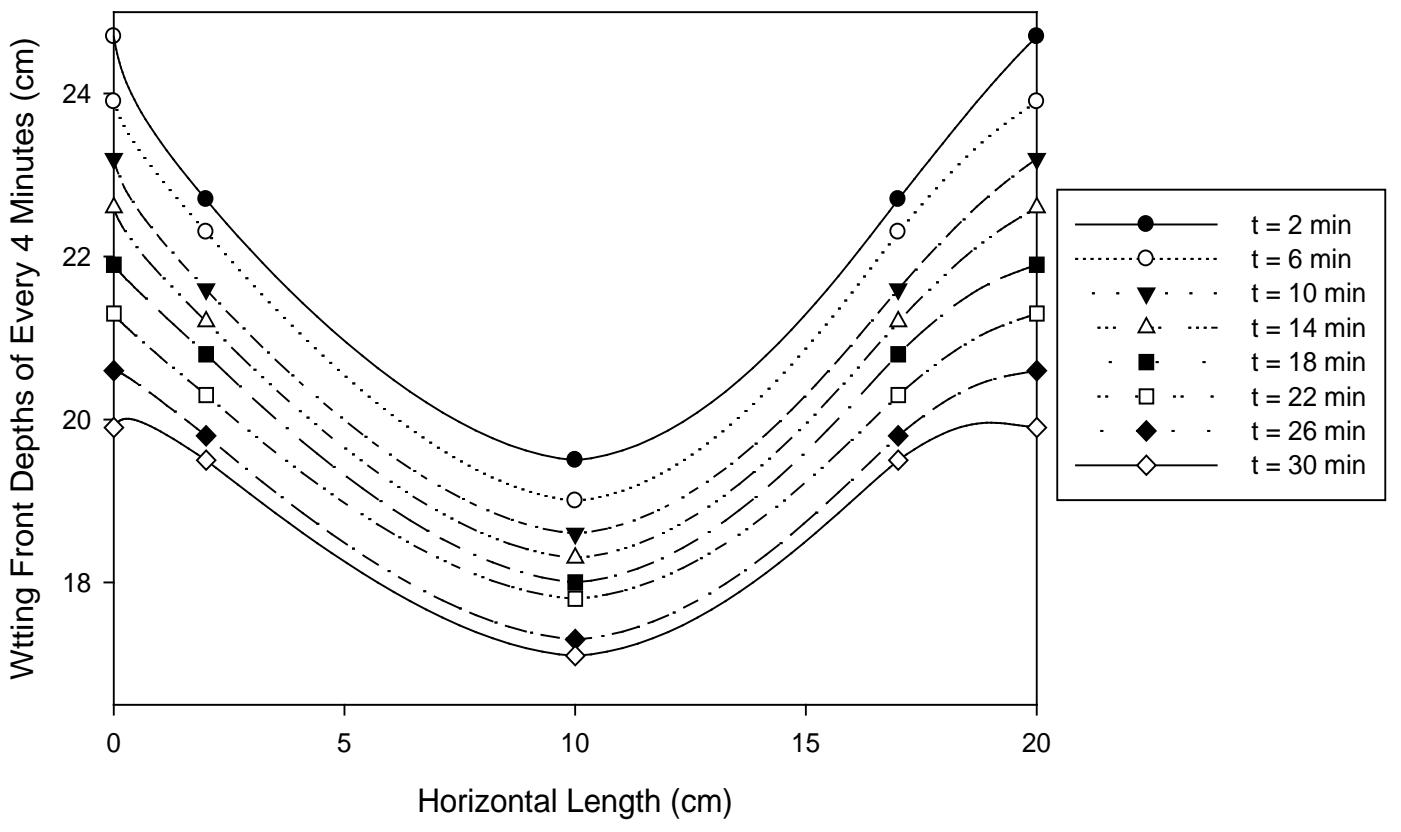

Fig. 3.15. Distribution of the experimental wetting fronts for silty clay soil (rainfall intensity = $0.040 \mathrm{~cm} / \mathrm{min}$; time interval $=4 \mathrm{~min}$; duration $=30 \mathrm{~min}$ ).

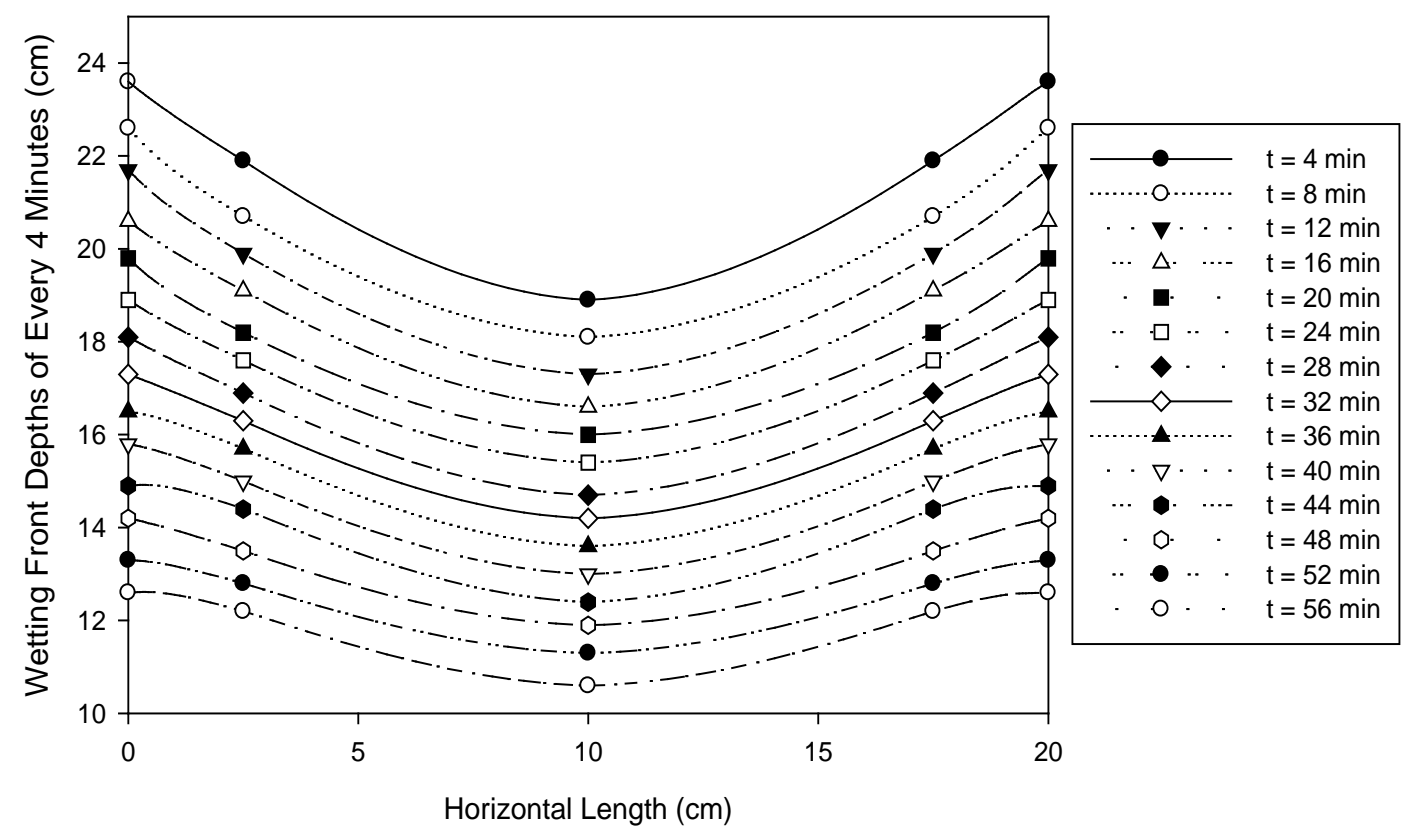

Fig. 3.16. Distribution of the experimental wetting fronts for loamy sand (rainfall intensity = $0.044 \mathrm{~cm} / \mathrm{min}$; time interval $=4 \mathrm{~min}$; duration $=56 \mathrm{~min}$ ). 


\subsubsection{Comparison of the experimental and modeling data}

The good agreement between the simulated and experimental wetting fronts for the three soil types can be observed (Fig. 3.17). All points are distributed closely along the 1:1 line for the three soil cases. Also, table 3.6 summarizes the quantitative evaluation of the modeling performance for the three soil types. The overall relative errors are $0.802 \%, 0.782 \%$, and $1.696 \%$ for silty clay loam, silty clay, and loamy sand, respectively. The Nash-Sutcliffe model efficiency coefficients in Table 3.6 demonstrate that all three models are almost equally successful. The values of RMSE are $0.210,0.211$, and 0.359 for the silty clay loam, silty clay, and loamy sand, respectively. In summary, good agreement between the observed and simulated wetting fronts has been achieved.
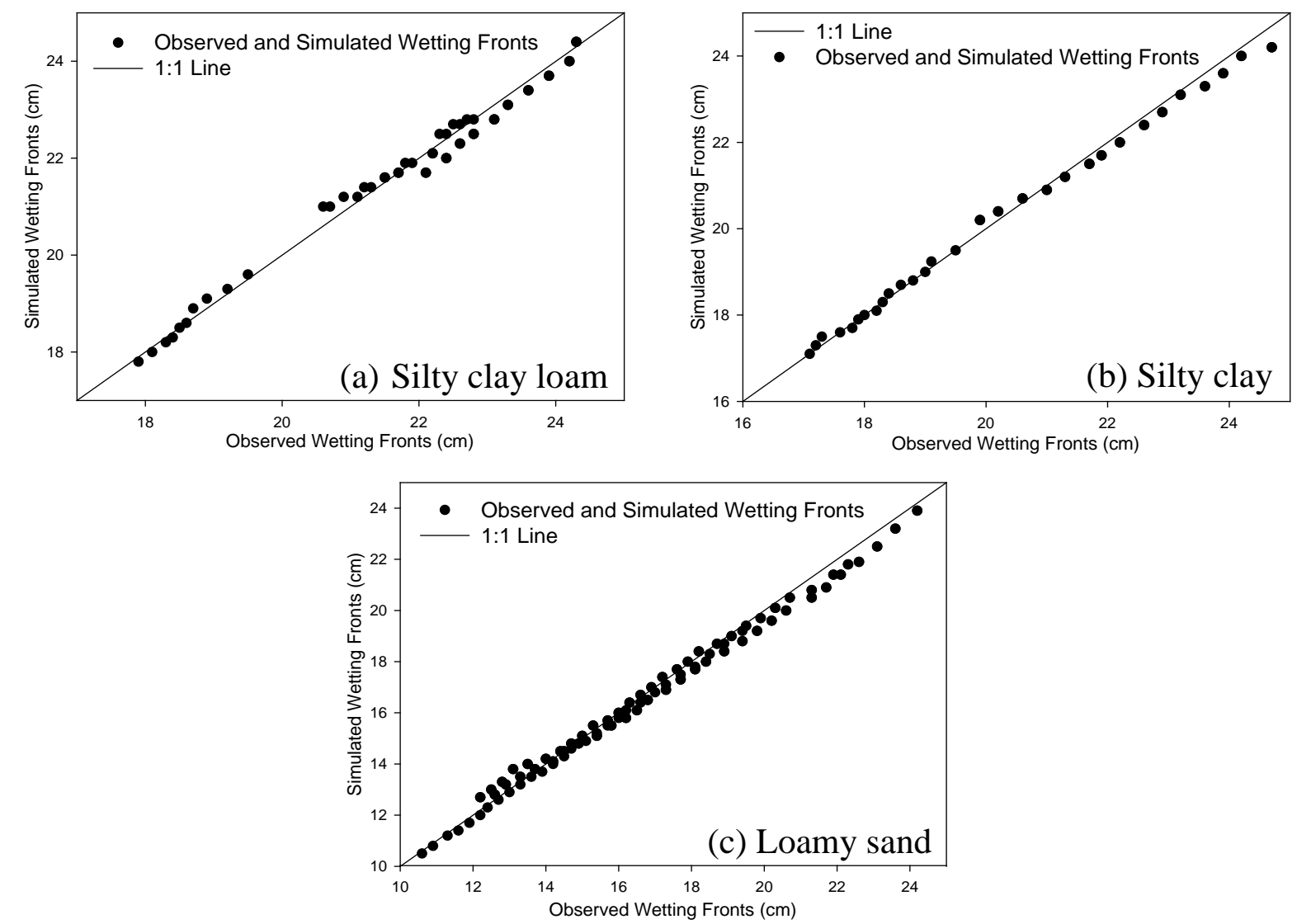

Fig. 3.17. Comparison between the observed and simulated wetting fronts for silty clay loam, silty clay, and loamy sand. 
Table 3.6. Quantitative evaluation of the model performance for the three soil types

\begin{tabular}{|c|c|c|c|}
\hline & Silty clay loam & Silty clay & Loamy sand \\
\hline ERR & $0.802 \%$ & $0.782 \%$ & $1.696 \%$ \\
\hline E & 0.986 & 0.987 & 0.988 \\
\hline RMSE & 0.210 & 0.211 & 0.359 \\
\hline
\end{tabular}

\subsubsection{Discussion on the effects of soil type on wetting front movement}

Fig. 3.18 depicts the standard deviation of the observed wetting front depths at all time steps for the three types of soil. Since the initial moisture content (IC) of the loamy sand is only $0.07 \mathrm{~cm}^{3} / \mathrm{cm}^{3}$ in the experiment, the standard deviation for the loamy sand soil is not comparable with that of the two other soils. Thus, the simulated data were used for loamy sand with IC = $0.15 \mathrm{~cm}^{3} / \mathrm{cm}^{3}$. In Fig. 3.18, a decreasing relationship can be observed for standard deviation and time, indicating that the spatial variation of wetting front decreases over time, which further implies that the wetting front gradually becomes horizontally flat.

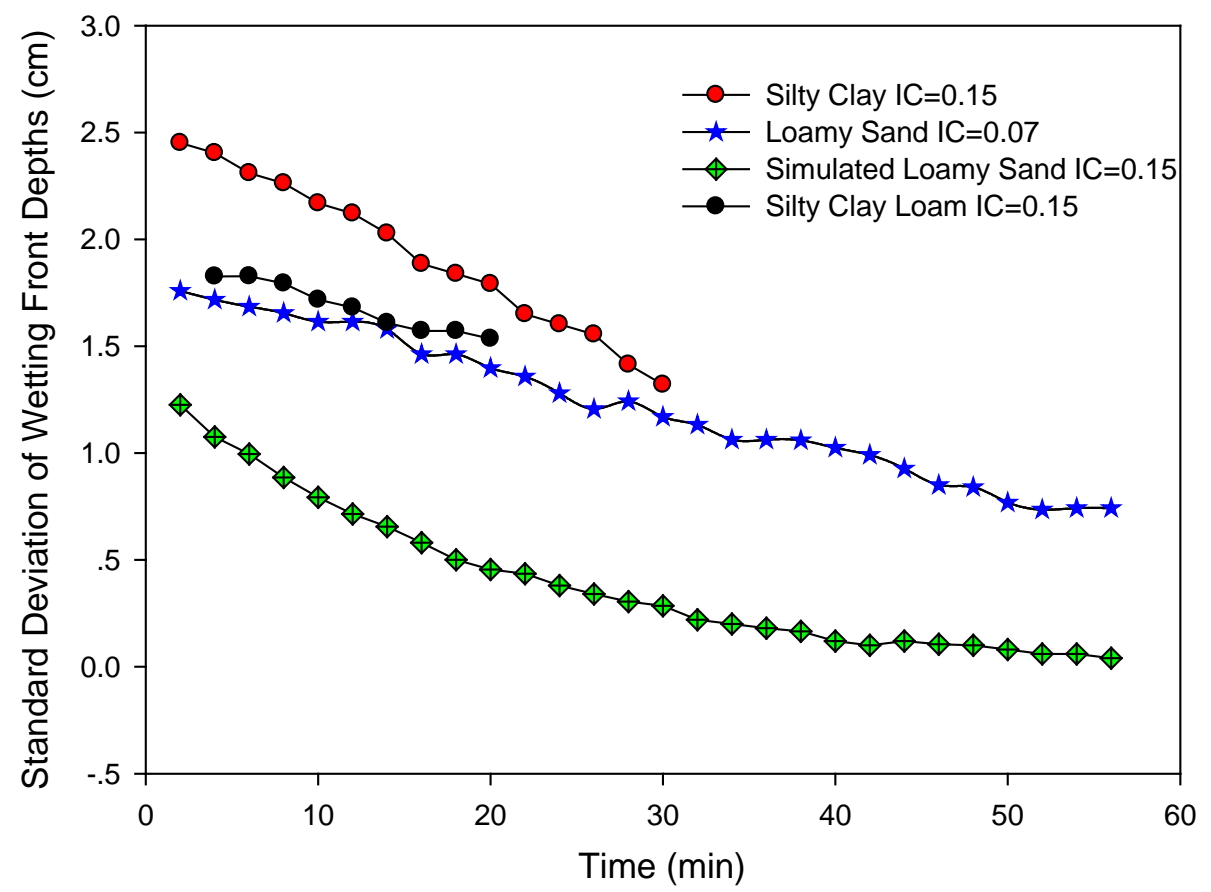

Fig. 3.18. Standard deviation of the observed wetting front depths for silty clay loam with an initial soil moisture content (IC) $=0.15 \mathrm{~cm}^{3} / \mathrm{cm}^{3}$, silty clay with IC $=0.15 \mathrm{~cm}^{3} / \mathrm{cm}^{3}$, and loamy sand with IC $=0.15 \mathrm{~cm}^{3} / \mathrm{cm}^{3}$ for simulation and IC $=0.07 \mathrm{~cm}^{3} / \mathrm{cm}^{3}$ for experiment. 
To further evaluate the effects of soil properties on wetting front movement under the concave surface, regression analysis was conducted for the three soil types. Table 3.7 shows the resulting regression equations. The slopes for the loamy sand and silty clay loam soils are very close. The standard deviation for silty clay has the greatest gradient among the three soil types. Thus, it takes less time for the wetting front to reach the uniformly distributed stage in the finer silty clay soil than in the two coarser soils (silty clay loam and loamy sand).

Table 3.7. Regression equations of standard deviations of wetting front depths (SD) vs. time (t) for silty clay loam, silty clay, and loamy sand soils

\begin{tabular}{|c|c|c|c|c|}
\hline & Silty clay loam & Silty clay & $\begin{array}{c}\text { Loamy sand } \\
\text { (initial moisture } \\
\text { content }=0.07 \text { ) }\end{array}$ & $\begin{array}{c}\text { Loamy sand } \\
\text { (initial moisture } \\
\text { content }=0.15 \text { ) }\end{array}$ \\
\hline $\begin{array}{c}\text { Linear } \\
\text { Regression }\end{array}$ & $\mathrm{SD}=-0.022 \mathrm{t}+$ & $\mathrm{SD}=-0.041 \mathrm{t}+$ & $\mathrm{SD}=-0.026 \mathrm{t}+$ & $\mathrm{SD}=-0.020 \mathrm{t}+$ \\
& 2.42 & 2.57 & 2.32 & 0.97 \\
\hline
\end{tabular}

With the same type of soil and surface microtopographic condition, the initial moisture content of loamy sand was changed from $0.07 \mathrm{~cm}^{3} / \mathrm{cm}^{3}$ to $0.15 \mathrm{~cm}^{3} / \mathrm{cm}^{3}$, leading to a slight difference in the slopes, but a great difference in the interceptions in both linear regression equations (Table 3.7). The higher initial soil moisture content of the same type of soil (i.e., loamy sand) indicated a smaller initial deviation of wetting front depth along the top soil boundary. In the succeeding time steps, however, the decreasing rates of the deviation of wetting front depths were very similar for the loamy sand soil with two different initial moisture conditions. To some extent, the changing rate of the wetting front depths was slower when the initial moisture content was higher. This can be attributed to the smaller soil matric potential resulting from the higher initial moisture content.

According to this study, a soil with a smaller particle size (e.g., silty clay) has stronger influences on the horizontal flow, which affects the spatial variations of wetting front movement. 
Thus, the decreasing rate of the standard deviation of wetting front depths for the silty clay soil is greater than that for the silty clay loam and loamy sand soils (Fig. 3.18 and Table 3.7). In addition, the slope of the linear SD-t regression equation (Table 3.7) for the silty clay loam (0.022) is lower than that of the loamy sand with IC $=0.07 \mathrm{~cm}^{3} / \mathrm{cm}^{3}(0.026)$ but higher than that of the loamy sand with IC $=0.15 \mathrm{~cm}^{3} / \mathrm{cm}^{3}(0.020)$, which indicates that the initial soil moisture content also plays a significant role in unsaturated soil-water flow under microtopographic surfaces. It can be concluded that the soil property has complex effects on soil unsaturated flow. Hence, the effects of different types of soil on wetting front movement under a rough microtopographic surface depend on various factors such as soil texture, initial soil moisture content, soil bulk density, pore network, and organic matter content. These complex effects result not only from one single aforementioned factor, but also from the combination of all potential factors.

\subsection{Modeling of Unsaturated Flow for Complex Topographic Surfaces}

The microtopography of a real surface is seldom similar to the one of the designed surfaces (the convex, flat, and concave surfaces) used in this study. In this section, HYDRUS 3D (Šimůnek et al. 2007) was applied to three different complex surfaces in order to verify the moving tendency of wetting front. The same soil type, rainfall intensity, boundary conditions, and initial soil moisture content were used in all simulations.

Silty clay soil from Buxton, ND was selected for this 3D modeling. A constant flux of $3.168 \mathrm{~cm} / \mathrm{h}$ and free drainage were respectively assumed for the top and bottom boundaries. Three real soil surfaces (RR1-RR3) with varying random roughness (Figs. 3.19a - c) were utilized for the 3D simulations. These surfaces had an area of $1.0 \times 0.8 \mathrm{~m}^{2}$ and the random 
roughness values for surfaces RR1, RR2, and RR3 were $1.30,0.80$, and $0.41 \mathrm{~cm}$, respectively (Yang and Chu 2012).
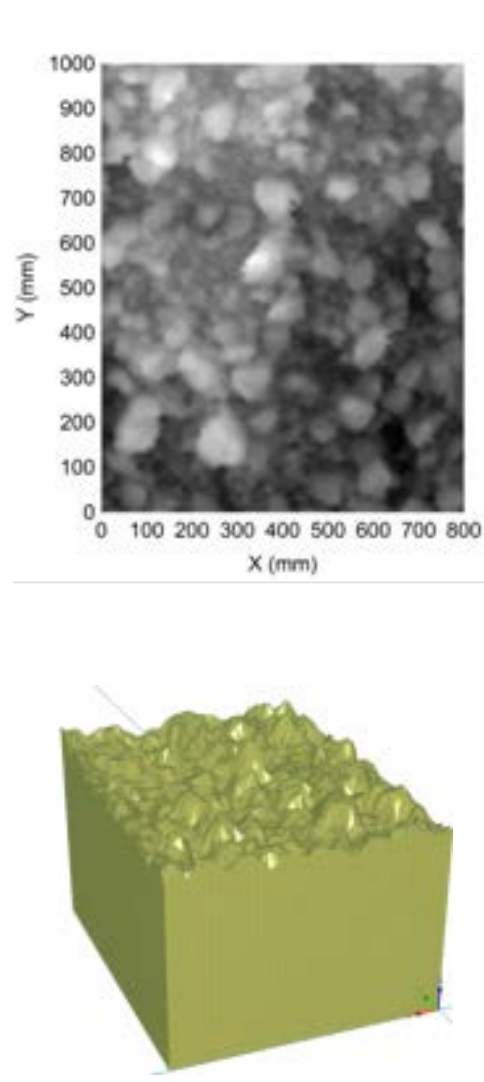

(a) Surface RR1

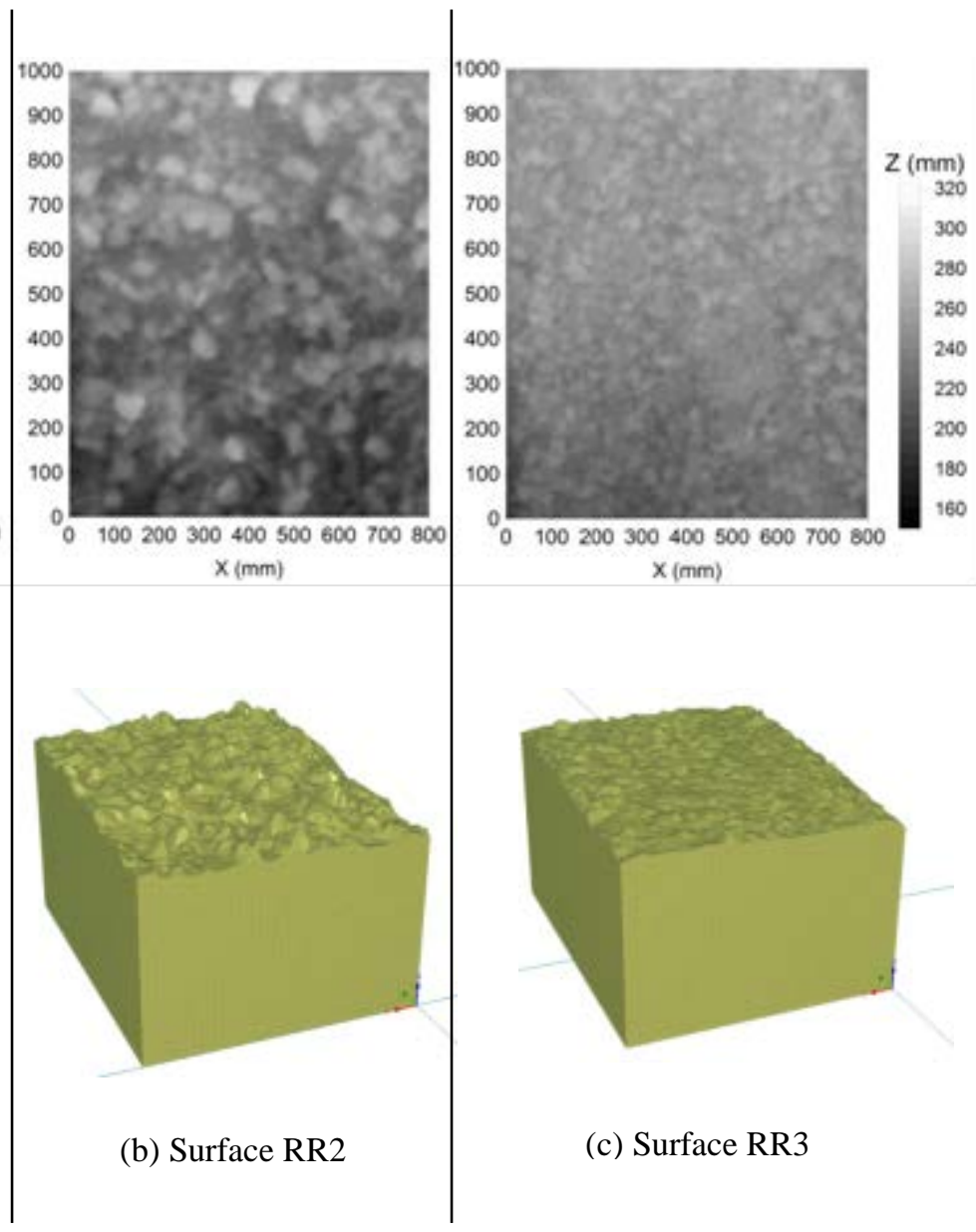

Fig. 3.19. Three random roughness soil surfaces used for the 3D simulations: (a) surface RR1, (b) surface RR2, and (c) surface RR3.

Fig. 3.20 shows the DEM profiles of the three random roughness surfaces (RR1-RR3) and the simulated wetting front distributions for $y=50.0 \mathrm{~cm}$ at three time points $(\mathrm{t}=15$, 30 , and $50 \mathrm{~min})$. It should be noted that the changing pattern of wetting front at $\mathrm{t}=0 \mathrm{~min}$ is the same as the surface microtopography. These wetting front curves for surfaces RR1 - RR3 demonstrate the overall changing pattern of wetting front over time (Fig. 3.20). That is, the spatial variations of the wetting fronts decrease over time as water moves downward. For instance, the wetting 
front distribution for surface RR3 is close to flat at $\mathrm{t}=45 \mathrm{~min}$; and the spatial variations in wetting front for RR1 and RR2 at $\mathrm{t}=45 \mathrm{~min}$ are not as significant as their initial patterns (Fig. 3.20). Nonetheless, some interested points on the wetting front curves don't follow this moving tendency (Fig. 3.20), which can be attributed to the complex moving directions of unsaturated flow in the horizontal plane. However, the general trend of the wetting front movement is apparent if a longer duration is considered.

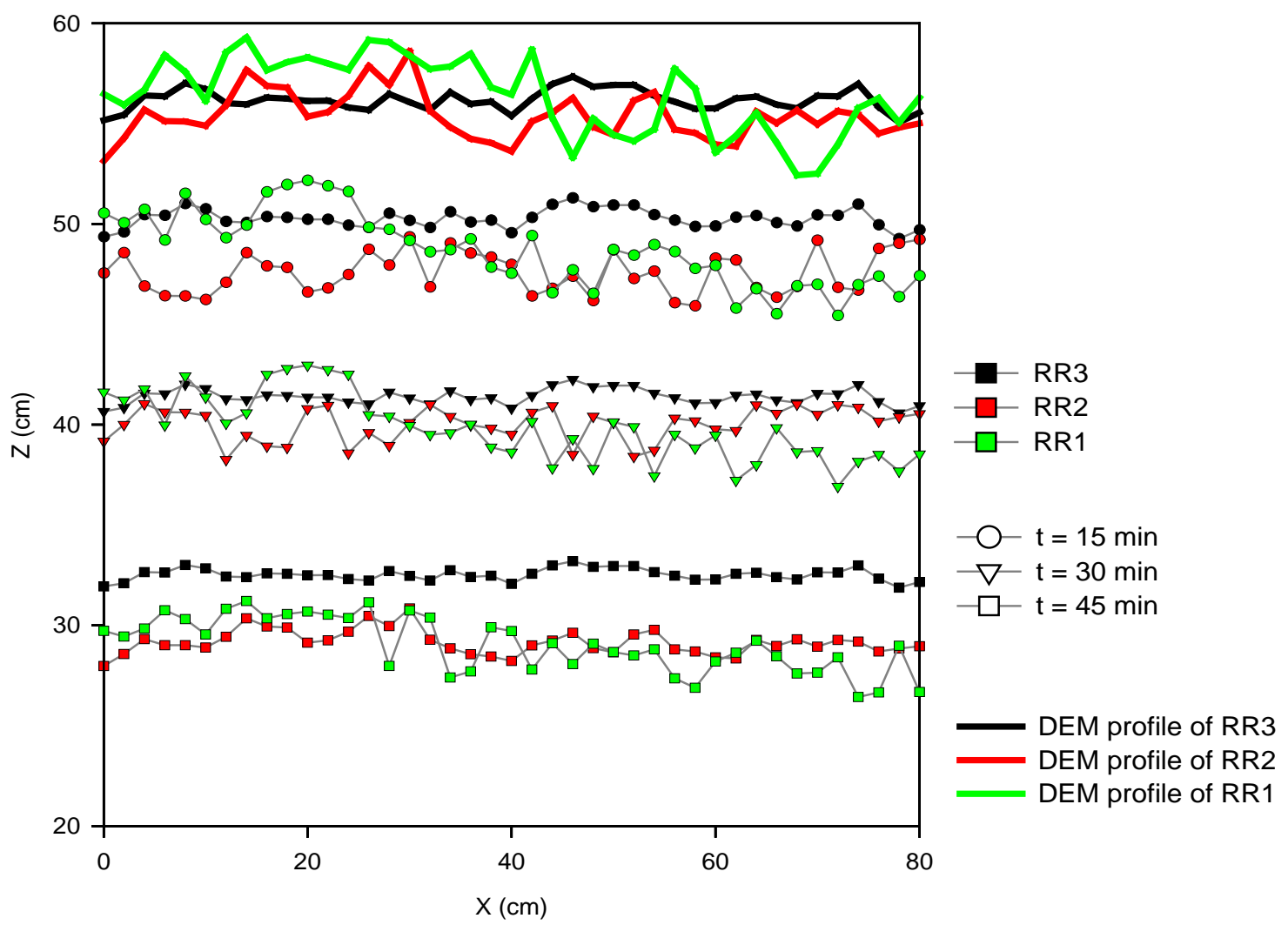

Fig. 3.20. Wetting front curves for surfaces RR1, RR2, and RR3 at $\mathrm{t}=15,30$, and $45 \mathrm{~min}(\mathrm{y}=$ $50.0 \mathrm{~cm})$.

To better display the general trend of the wetting front movement under the three rough surfaces, the standard deviations of the spatial changes in wetting front depths at four selected time points $(t=0,15,30$, and $50 \mathrm{~min})$ are shown in Fig. 3.21. Initially $(t=0 \mathrm{~min})$, surface RR1 
has the highest variations in wetting front than surfaces RR2 and RR3. The standard deviations of wetting front depths for surfaces RR1, RR2, and RR3 decrease from 1.9 to $1.3 \mathrm{~cm}$, from 1.1 to $0.6 \mathrm{~cm}$, and from 0.5 to $0.3 \mathrm{~cm}$, respectively. Hence, surfaces with smaller roughness require much less time to form a horizontally uniform wetting front.

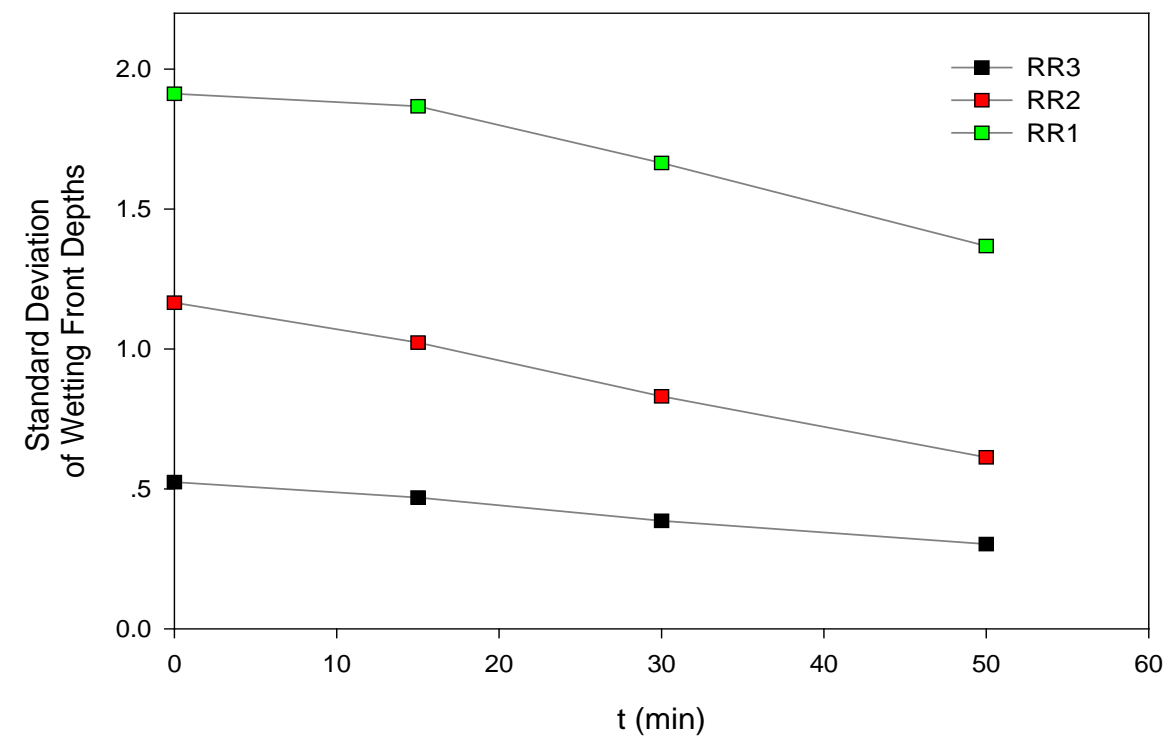

Fig. 3.21. Standard deviation of wetting front depths for surfaces RR1, RR2, and RR3 at $t=15$, 30 , and $50 \mathrm{~min}(\mathrm{y}=50.0 \mathrm{~cm})$. 


\section{CHAPTER 4. SUMMARY AND OVERALL CONCLUSIONS}

The major objective of this thesis study was to evaluate the influence of surface microtopography on wetting front movement with a special focus on the spatial and temporal changing patterns of wetting front. Laboratory experiments were first conducted for three different topographic surfaces (concave, convex, and flat surfaces) under the same rainfall and soil conditions. Then, the influences of rainfall intensity and soil type on microtopographyinfluenced wetting front movement were investigated under the same microtopographic condition. In addition, two-dimensional modeling was conducted by using the HYDRUS software to simulate infiltration and unsaturated flow for all the three topographic surfaces. The modeling results were compared with the observations and good agreement was achieved. Furthermore, HYDRUS 3D modeling was performed for three complex microtopographic surfaces with varying random roughness.

It was observed that as water infiltrated into a curved soil surface (concave or convex surface), the wetting front was initially parallel to the surface, but gradually became even and flat over time and approached to a uniform distribution, even though the wetting front was nonuniformly distributed at the early stage because of the spatial variation of surface microtopography. During this process, soil matric force played an important role to control the unsaturated soil-water flow and its directions, especially along the horizontal directions. The unsaturated soil-water flow followed a radial direction to form a diverging or converging path along the arc boundary (i.e., concave or convex surface). It can be concluded that the larger the radian was; the stronger the horizontal flow was. Moreover, the soil matric potential strengthened the unsaturated flow in the horizontal direction especially under a surface that had significant variability in microtopography. Hence, a surface with greater topographic variations 
(a rougher surface) needed more time to balance the difference of soil moisture in the horizontal direction. In the 2D models, the soil-water flow effectively reduced the soil moisture differences in the horizontal direction over time. Such soil moisture differences were directly related to the spatial variations of surface microtopography. As a result, the wetting front eventually became flat and even (i.e., a horizontal plane) under the curved (convex and concave) microtopographic surfaces. In the 3D modeling, very complex moving directions of unsaturated flow existed in the horizontal plane. Therefore, the moving tendency of wetting front was not obvious within short time, while the general trend of the wetting front movement was apparent for a longer duration.

The spatial and temporal changing patterns of wetting front were examined in both laboratory experiments and HYDRUS modeling. The timing to become a leveled wetting front varied due to the factors such as rainfall intensity and soil property under the same surface microtopography. Compared with the light and moderate rainfall events, it took less time for the wetting front to reach a uniform stage for the curved surfaces (concave and convex surfaces) under the heavy rainfall. Moreover, the final wetting front under the moderate rainfall was more uniformly distributed than the one under the light rainfall, even though the duration of the moderate rainfall was shorter than that of the light rainfall. It can be concluded that heavier rainfall can strongly expedite the formation of the uniformly distributed wetting front.

Soil property was another control factor that was considered in this study to evaluate the changing patterns of wetting front movement. Different from the loamy sand and silty clay loam soils, the wetting front for the silty clay soil showed the fastest moving tendency of becoming flat because of its relatively smaller particle size, which strengthened the horizontal unsaturated soil flow to form a uniformly distributed wetting front. This stronger horizontal flow contributed to a greater changing rate for the non-uniform wetting-front to become uniformly distributed. 
For the same type of soil with different initial moisture contents, to some extent, the changing rate was lower when the initial moisture content was higher. However, the effect of soil on the unsaturated flow was very complicated under rough surface microtopography. It is insufficient to evaluate the effects of soil texture and initial soil moisture content individually. The combined influence of all the potential factors should also be taken into account.

Even though several major conclusions have been obtained from this thesis research, there are some limitations in the current study. To simplify the problem, the post-ponding condition is not considered. Under this condition, the actual infiltration rate is equal to the rainfall intensity. The changing of infiltration is not able to be estimated. In addition, the spatial scale of this study is relatively small and the surfaces used in the three scenarios are simple. More work is needed to deal with various surface microtopography and surface ponding conditions. Besides, measurement of the infiltration rates would improve the understanding of the wetting front movement influenced by surface microtopography. 


\section{REFERENCES}

Aguilar, M.A., Aguilar, F., and Negreiros, J. (2009). “Off-the-shelf laser scanning and closerange digital photogrammetry for measuring agricultural soils microrelief.” Biosystems Engineering, 103(4), 504-517.

Allmaras, R.R., Burwell, R.E., Larson, W.E., and Holt, R.F. (1966). “Total porosity and random roughness of the interrow zone as influenced by tillage.” USDA Conservation Research Report 7, Washington, D.C.: USDA Agricultural Research Service, 1-14.

Allmaras, R.R., Nelson, W.W., and Hallauer, E.A. (1972). Fall versus spring plowing and related soil heat balance in the western Corn Belt. Minnesota Agricultural Experiment Station (MAES), University of Minnesota, St. Paul, MN, 1-22.

Bergkamp, G. (1998). “A hierarchical view of the interactions of runoff and infiltration with vegetation and microtopography in semiarid shrublands.” Catena, 33(3-4), 201-220.

Beven, K. and Kirkby, M.J. (1979). “A physically-based, variable contributing area model of basin hydrology.” Hydrological Sciences Bulletin, 24(1), 43-69.

Biemelt, D., Schapp, A., Kleeberg, A., and Grünewald, U. (2005). “Overland flow, erosion, and related phosphorus and iron fluxes at plot scale: A case study from a non-vegetated lignite mining dump in Lusatia.” Geoderma, 129(1-2), 4-18.

Burt, T P. and Butcher, D.P. (1985). “Topographic controls of soil-moisture distributions.” European Journal of Soil Science, 36(3), 469-486.

Chi, Y., Yang, J., Bogart, D., and Chu, X. (2012). “Fractal analysis of surface microtopography and its application in understanding hydrologic processes.” Transactions of the ASABE, 55(5), 1781-1792. 
Chu, X., Yang, J., and Chi, Y. (2012). "Quantification of soil random roughness and surface depression storage: methods, applicability, and limitations." Transactions of the ASABE, 55(5), 1699-1710.

Chu, X., Zhang, J., Yang, J., and Chi, Y. (2010). “Quantitative evaluation of the relationship between grid spacing of DEMs and surface depression storage.” Proceedings of the 2010 World Environment and Water Resources Congress, ASCE, Reston, VA, 4447-4457.

Darboux, F., Davy, P., Gascuel-Odoux, C., and Huang, C. (2002). “Evolution of soil surface roughness and flowpath connectivity in overland flow experiments.” Catena, 46(2-3), 125139.

Dixon, B. and Earls, J. (2009). "Resample or not?! Effects of resolution of DEMs in watershed modeling.” Hydrological Processes, 23(12), 1714-1724.

Dunne, T., Zhang, W., and Aubry, B.F. (1991). "Effects of rainfall, vegetation, and microtopography on infiltration and runoff.” Water Resources Research, 27(9), 2271-2285.

Esteves, M., Faucher, X., Galle, S., and Vauclin, M. (2000). “Overland flow and infiltration modeling for small plots during unsteady rain: Numerical results versus observed values.” Journal of Hydrology, 228(3-4), 265-82.

Fiedler, F.R. and Ramirez, J.A. (2000). “A numerical method for simulating discontinuous shallow flow over an infiltrating surface.” International Journal for Numerical Methods in Fluids, 32(2), 219-39.

Fox, D.M., Bryan, R.B., and Price, A.G. (1997). “The influence of slope angle on final infiltration rate for interrill conditions.”Geoderma, 80(1-2), 181-194.

Fox, D.M., Le Bissonnais, Y., and Bruand, A. (1998). "The effect of ponding depth on infiltration in a crusted surface depression." Catena, 32(2), 87-100. 
Gómez, J.A. and Nearing, M.A. (2005). "Runoff and sedimentation losses from rough and smooth soil surfaces in a laboratory experiment.” Catena, 59(3), 253-266.

Green, I.R.A. and Stephenson, D. (1986). "Criteria for comparison of single event models.” Hydrological Sciences Journal, 31, 395-411.

Guzha, A.C. (2003). "Effects of tillage on soil microrelief, surface depression storage and soil water storage.” Soil and Tillage Research, 76(2), 105-114.

Haggard, B.E., Moore Jr, P.A., and Brye, K.R. (2005). “Effect of slope on runoff from a small variable box-plot.” Journal of Environmental Hydrology, 25(13), 1-8.

Hairsine, P.B., Noran, C.J., and Rose, C.W. (1992). "Recent developments regarding the influence of soil surface characteristics on overland flow and erosion.” Australian Journal of Soil Research, 30(3), 249-264.

Hansen, B., SchÖning, P., and Sibbesen, E. (1999). “Roughness indices for estimation of depression storages capacity of tilled soil surfaces.” Soil and Tillage Research, 52(1-2), 103-111.

Hassan, G., Persaud, N., and Reneau, R.B. Jr. (2005). "Utility of hydrus-2D in modeling profile soil moisture and salinity dynamics under saline water irrigation of soybean." Soil Science, 170(1), 28-37.

Hillel, D. (1998). Environmental Soil Physics: Fundamentals, Applications, and Environmental Considerations. Academic Press, San Diego, CA, 1-771.

Huang, C. and Bradford, J.M. (1990). "Depressional storage for Markov-Gaussian surface.” Water Resources Research, 26(9), 2235-2242.

Huang, C., and Bradford, J.M. (1992). “Application of a laser scanner to quantify soil microtopography.” Soil Science Society of America Journal, 56(1), 14-21. 
Jacques, D., Šimůnek, J., Timmerman, A., and Feyen, J. (2002). “Calibration of Richards' and convection-dispersion equations to field-scale water flow and solute transport under rainfall conditions.” Journal of Hydrology, 259(1-4), 15-31.

Jordan, J. P. (1994). "Spatial and temporal variability of stormflow generation processes on a Swiss catchment.” Journal of Hydrology, 153(1-4), 357-382.

Kamphorst, E.C., Jetten, V., Guerif, J., Pitkanen, J., Iversen, B.V., Douglas, J.T., and Paz, A. (2000). "How to predict maximum water storage in depressions from soil roughness measurements.” Soil Science Society of America Journal, 64(5), 1749-1758.

Kirkham, M.B. (2005). Principles of soil and plant water relations. Academic Press, Boston, MA, 145-172.

Köhne, J.M., Wöhling, T., Pot, V., Benoit, P., Leguédois, S.Y., Bissonnais, Y.L., and Šimůnek, J. (2011). “Coupled simulation of surface runoff and soil water flow using multiobjective parameter estimation.” Journal of Hydrology, 403(1-2), 141-156.

Lee, G., Tachikawa, Y., and Takara, K. (2009). "Interaction between topographic and process parameters due to the spatial resolution of DEMs in distributed rainfall-runoff modeling." Journal of Hydrologic Engineering, 14(10), 1059-1069.

Lei, T.W., Pan, Y.H., Liu, H., Zhan, W.H., and Yuan, J.P. (2006). “A run off-on-ponding method and models for the transient infiltration capability process of sloped soil surface under rainfall and erosion impacts." Journal of Hydrology, 319(1-4), 216-226.

Lipsius, K. and Mooney, S.J. (2006). "Using image analysis of tracer staining to examine the infiltration patterns in a water repellent contaminated sandy soil.” Geoderma, 136(2), 865875. 
McGuire, K.J., McDonnell, J.J., Weiler, M., Kendall, C., McGlynn, B.L., Welker, J.M., and Seibert, J. (2005). “The role of topography on catchment-scale water residence time.” Water Resources Research, 41(5), DOI: 10.1029/2004WR003657.

Meyer, L.D. and Harmon, W. C. (1979). “Multiple-intensity rainfall simulator for erosion research on row sideslopes.” Transactions of the ASAE, 22(1), 100-103.

Mitchell, J.K. and Jones Jr, B.A. (1978). “Micro-relief surface depression storage: changes during rainfall events and their application to rainfall-runoff models.” Journal of the American Water Resources Association, 14(4), 777-802.

Moore, D.C. and Singer, M.J. (1990). “Crust formation effects on erosion processes.” Soil Science Society of America Journal, 54(4), 1117-1123.

Moore, R.D. and Thompson, J.C. (1996). “Are water table variations in a shallow forest soil consistent with the TOPMODEL concept?” Water Resources Research, 32(3), 663-669.

Musgrave, G.W. (1955). How much of the rain enters the soil? Water Yearbook of Agriculture, U.S. Department of Agriculture (USDA), Washington, DC. pp. 151-159.

Nash, J.E. and Sutcliffe, J.V. (1970). "River flow forecasting through conceptual models part I A discussion of principles.” Journal of Hydrology, 10 (3), 282-290.

Onstad, C.A. (1984). “Depressional storage on tilled soil surfaces.” Transactions of the ASAE, 27(3), 729-732.

Philip, J. R. (1969). “Theory of infiltration.” Advances in Hydroscience, 5(1), 216-291

Philip, J.R. (1957). “The theory of infiltration: 1. the infiltration equation and its solution.” Soil Science, 83(5), 345-357.

Planchon, O., Esteves, M., Silvera, N., and Lapetite, J. M. (2001). “Microrelief induced by tillage: measurement and modeling of surface storage capacity.” Catena, 46(2001), 141-157. 
Price, K. (2011). “Effects of watershed topography, soils, land use, and climate on baseflow hydrology in humid regions: A review.” Progress in Physical Geography, 35(4), 465-492.

Price, K., Jackson, C.R., Parker, A.J., Reitan, T., Dowd, J., and Cryterski, M. (2011). “Effects of watershed land use and geomorphology on stream low flows during severe drought conditions in the southern Blue Ridge Mountains, GA and NC, USA.” Water Resources Research 47(2), W02516.

Radcliffe, D.E. and Šimůnek, J. (2010). Soil physics with HYDRUS: Modeling and applications. CRC Press, Boca Raton, FL, 61-88.

Richards, L.A. (1931). “Capillary conduction of liquids through porous mediums.” Ph.D. dissertation, Cornell University, Ithaca, NY.

Rocha, D., Abbasi, F., and Feyen, J. (2006). "Sensitivity analysis of soil hydraulic properties on subsurface water flow in furrows.” Journal of Irrigation and Drainage Engineering, ASCE, 132(4), 418-424.

Rodhe, A., Nyberg, L., and Bishop, K. (1996). “Transit times for water in a small till catchment from a step shift in the oxygen 18 content of the water input.” Water Resources Research, 32(12), 3497-3511.

Römkens, M.J.M. and Wang, J.Y. (1986). “Effect of tillage on surface roughness.” Transactions of the ASCE, 29(2), 429-433.

Rossi, M. J. and Ares, J. O. (2012). “Depression storage and infiltration effects on overland flow depth-velocity-friction at desert conditions: field plot results and model.” Hydrology and Earth System Sciences, 16, 3293-3307.

Sande, L. (2011). “Experimental studies on infiltration/soil-water movement processes and Green-Ampt modeling.” M.S. thesis, North Dakota State University, Fargo, ND. 
Sande, L. and Chu, X. (2012). “Laboratory experiments on the effect of microtopography on soil-water movement: Spatial variability in wetting front movement.” Applied and Environmental Soil Science, Volume 2012, Article ID 679210, 8 pages, doi:10.1155/2012/679210.

Sande, L., Chu, X, and DeSutter, T. (2011). “A new method for replicating complex microtopographic surfaces in laboratory soil box experiments.” Applied Engineering in Agriculture, 27(4), 615-620.

Schaap, M.G, Leij, F.J., and van Genuchten, M.T. (2001). "ROSETTA: a computer program for estimating soil hydraulic parameters with hierarchical pedotransfer functions." Journal of Hydrology, 251(3-4), 163-176.

Schmalz, B., Lennartz, B., and van Genuchten, M.Th. (2003). “Analysis of unsaturated water flow in a large sand tank.” Soil Science, 168(1), 3-14.

Shmuel, A. (2013) “Infiltration into soils: Conceptual approaches and solutions.” Water Resources Research, 49(4), 1-18.

Šimůnek, J., van Genuchten, M.T., and Šejna, M. (2007). The HYDRUS software packages for simulating the two- and three-dimensional movement of water, heat, heat, and multiple solutes in variably-saturated media: User Manual, Version 1.02. Department of Environmental Sciences, University of California, Riverside, CA, 1-28.

Šimůnek, J., van Genuchten, M.Th., and Šejna, M. (1998). The HYDRUS-1D software package for simulating the one-dimensional movement of water, heat, and multiple solutes in variably-saturated media. Version 1.0, IGWMC-TPS-70. International Ground Water Modeling Center, Colorado School of Mines, Golden, CO, 1-186. 
Šimůnek, J., van Genuchten, M.Th., and Šejna, M. (1999). The Hydrus-2D software package for simulating two-dimensional movement of water, heat, and multiple solutes in variably saturated media. Version 2.0, IGWMC-TPS-53. International Ground Water Modeling Center, Colorado School of Mines, Golden, CO, 1-24.

Šimůnek, J., van Genuchten, M.Th., and Šejna, M. (2005). The HYDRUS-1D software package for simulating the one-dimensional movement of water, heat, and multiple solutes in variably saturated media. Version 3.0, HYDRUS Software Series 1. Department of Environmental Sciences, University of California, Riverside, CA, 1-43.

Šimůnek, J., van Genuchten, M.Th., and Šejna, M. (2008). "Development and applications of the HYDRUS and STANMOD software packages, and related codes.” Vadose Zone Journal, 7(2), 587-600.

Sinai, G. and Dirksen, C. (2006). "Experimental evidence of lateral flow in unsaturated homogeneous isotropic sloping soil due to rainfall”. Water Resources Research, 42(12), W12402, doi:10.1029/2005WR004617.

Skaggs, T.H., Trout, T.J., Šimůnek, J., and Shouse, P.J. (2004). "Comparison of HYDRUS-2D simulations of drip irrigation with experimental observations." Journal of Irrigation and Drainage Engineering, ASCE, 130(4), 304-310.

Smith, M.W., Cox, N.J., and Bracken, L.J. (2011). “Terrestrial laser scanning soil surfaces: a field methodology to examine soil surface roughness and overland flow hydraulics.” Hydrological Processes, 25(6), 842-860.

Thompson, S.E., Katul, G.G., and Porporato, A. (2010). "Role of microtopography in rainfallrunoff partitioning: An analysis using idealized geometry.” Water Resources Research, 46(7), W07520, doi:10.1029/2009WR008835. 
van Genuchten, M.Th. (1980). “A closed-form equation for predicting the hydraulic conductivity of unsaturated soils.” Soil Science Society of America Journal, 44 (5), 892-898.

van Schaik, N.L.M.B. (2009). "Spatial variability of infiltration patterns related to site characteristics in a semi-arid watershed.” Catena, 78, 36-47.

Vázquez Vidal, E., Vivas Miranda, J.G., and Paz González, A. (2005). “Characterizing anisotropy and heterogeneity of soil surface microtopography using fractal models.” Ecological Modelling, 182(3-4), 337-353.

Western, A.W., Blöschl, G., and Grayson, R.B. (2001). “Toward capturing hydrologically significant connectivity in spatial patterns.” Water Resources Research, 37(1), 83-97.

Yang, J. and Chu, X. (2012). “Effects of Surface Microtopography on Hydrologic Connectivity.” p339-348. In: Crossing Boundaries, Proceedings of the 2012 ASCE World Environmental and Water Resources Congress, Edited by E. D. Loucks. American Society of Civil Engineers.

Yu, C. and Zheng, C. (2010). “HYDRUS: Software for flow and transport modeling in variably saturated media.” Ground Water, 48(6), 797-791.

Zhou, Q.Y., Kang, S.Z., Zhang, L., and Li, F.S. (2007). "Comparison of APRI and Hydrus-2D models to simulate soil water dynamics in a vineyard under alternate partial root zone drip irrigation." Plant and Soil, 291(1-2), 211-223.

Zhu, J and Mohanty, B.P. (2006). “Effective scaling factor for transient infiltration in heterogeneous soils.” Journal of Hydrology, 319(1-4), 96-108.

Zobeck, T.M. and Onstad, C.A. (1987). “Tillage and rainfall effects on random roughness: A review.” Soil and Tillage Research, 9(1), 1-20. 